\title{
Suppliers Dynamic Approach to Invest in R\&D with Sunk Costs in Indian Contexts
}

\author{
Manoj KUMAR ${ }^{*}$, Jyoti RAMAN ${ }^{* *}$, Priya RAMAN ${ }^{* * *}$
}

\begin{abstract}
In this paper we test for the presence of sunk costs in suppliers' R\&D activities by analyzing the persistence of these activities using supplier level panel data. We develop and estimate a dynamic discrete choice model where each supplier's current $R \& D$ expenditure is a function, among other factors, of its previous experience in performing $R \& D$ activities. The data used is a panel data of Indian suppliers, for the period 2003 - 2013. We find that prior $R \& D$ experience significantly affects the current decision to invest in $R \& D$, and that, although important, the effect of prior $R \& D$ experience depreciates fairly quickly over time.
\end{abstract}

Keywords: R\&D Decision, Persistence, Sunk Costs, Panel Data, Multivariate Dynamic Binary Choice Model

JEL Code Classification: 032

UDC: 336.581.1:001(540)

\footnotetext{
"Corresponding author, International Engineering Services, India. Email:kumarm1968@rediffmail.com

** International Engineering Services, India. Email: jyotiraman2004@rediffmail.com

${ }^{* * *}$ International Engineering Services, India. E-mail:priyaraman2006@rediffmail.com 


\section{Introduction}

Understanding the determinants of suppliers' R\&D investments has received much attention among researchers and policy makers. More recently, the analysis has focused on the complexity of the process of innovation by suppliers and the heterogeneous nature of R\&D activities. In particular, a number of papers have examined the determinants of the different alternatives suppliers face once they have decided to invest in R\&D. The choice between own generation of technology or its external acquisition has been analyzed, among others, by Beneito (2002, 2003). The development of R\&D activities may involve creating an R\&D department and hiring or training specialized workforce, which are start-up costs that in turn may be consider as sunk costs. This is related to the fact that a minimum period of maturity is needed for the R\&D expenditures of the supplier to translate into an innovating output with a positive impact on profits, which usually implies that the supplier chooses its R\&D trajectory within a medium or long run perspective. These distinctive features of the innovating activities suggest the existence of sunk costs associated with the performance of R\&D activities.

In spite of the large number of papers analyzing the determinants of suppliers' decision to invest in R\&D, to our knowledge, the role of sunk costs in shaping this decision has not yet been explicitly analyzed.

It is important to note that persistence in performing R\&D activities might be caused by sunk costs but also by underlying (observed and unobserved) firm heterogeneity (i.e., persistent differences across firms in the gross profit from R\&D investments) or serial correlation in exogenous shocks. Persistence in behavior due to permanent differences in profitability across firms could create the appearance of sunk costs in the model. Therefore, to properly identify the role of sunk costs we use an econometric framework that allows controlling for all competing sources of persistence in the R\&D investments. The data used is a panel data of Indian suppliers, for the period 1993-2013. This is the first attempt to analyze the role of sunk costs in supplier's decision to invest in R\&D using a dynamic approach and accounting for a wide range of suppliers characteristics. To anticipate our results, we find that prior R\&D experience significantly affects the current decision to invest in $R \& D$, and that, although important, the effect of prior R\&D experience depreciates fairly quickly over time.

The rest of the paper is organized as follows. In section 2, we provide literature review. In section 3 we discuss the characteristics of our sample and analyze R\&D patterns for Indian suppliers. In section 4 we discuss the R\&D efficiency. Section 5 introduces an empirical model of entry and exit in R\&D activities with explicit consideration of the role of sunk costs. In section 6 , we describe the explanatory variables. The estimation results are summarized in section 7. Finally, section 8 concludes. 


\section{Literature review}

There is a body of literature in which suppliers technological advancement is conceptualized as a learning process (Hitt et. al., 2000). Czarnitzki et al. (2007) study the impact of R\&D subsidy policy and of voluntary R\&D collaboration on R\&D investment and on patents in two countries, Germany and Finland. Clarysse et al. (2009) focused on the behavioral effect of subsidy policy and defined it as the changes in management practices of innovation process within the company. Other scholars (Cerulli and Potì, 2012) have provided some improvement by adopting a two-step method which assesses the policy capacity to foster innovation via its ability to firstly promote companies $R \& D$ innovation activity additionality.

In the game theory literature of innovation, a number of papers have considered the association between the innovation activity and sunk costs. More recently, Kaplan, Luski and Wettstein (2003) present a game theoretical model where all suppliers compete to be the first to innovate and earn the whole reward (patent) incurring in a cost that is sunk and thus independent of which supplier wins the race. Aw, Roberts, and Xu (2011) estimate a dynamic model of export choice and R\&D investment using supplier data for Taiwanese electronics producers.

\section{The data}

To analyse the determinants of suppliers' R\&D decisions we use data drawn from, an annual survey of Indian suppliers carried out by the Ministry of Industry since 2003. The survey is representative of the Indian suppliers classified by industrial sector and size categories and includes exhaustive information at the supplier level. The sampling procedure of the survey is the following. In the base year, 2003, suppliers were chosen using a selective sampling scheme with different participation probabilities depending on the supplier size category. All suppliers with more than 200 employees (large firms) were requested to participate and the participation rate reached approximately $70 \%$ of the number of suppliers in the population. Suppliers that employed from 10 to 200 (small suppliers) were randomly sampled by industry and size strata (according to 20 different productive activities and 4 size intervals), holding around a $5 \%$ of the population. Suppliers with less than 10 employees are excluded from the survey. Hence, the coverage of the dataset is different depending on the size group of suppliers. The different sampling properties of these two size groups as well as the possible relationship between size and the R\&D decision advice to carry out a separate analysis of the representativeness of the sample and transitions in and out of R\&D activities by size group. Furthermore, the influence of size in the R\&D decision will be taken into account in our econometric analysis.

In our work we use a panel of continuously operating suppliers from 2003 to 2013. The choice of a continuous panel is motivated by two reasons. First, to analyse supplier R\&D trajectories for as many years as possible we sample out those suppliers that fail to supply R\&D information in any given year of the sampling 
period. Second, given our need to estimate a dynamic specification with lagged endogenous variables, we would like to build up a panel as long as possible. Furthermore, we drop any supplier that failed during the sampling period.

After applying these criteria, we end up with a balanced panel of 757 suppliers that is not necessarily representative of the complete survey sample. This is the sample we use in our analysis. Table 1 shows that in our sample small suppliers are slightly over-represented if compared to the complete sample: in 2003, both the proportion of suppliers and the share of the small suppliers group in employment, sales and R\&D expenditure are larger in our sample than in the complete survey sample. On average, in our selected sample, small suppliers represent $13.34 \% \%$ of total employment, $11.46 \%$ of total sales and $4.68 \%$ of total R\&D expenditure.

Table 1: Sample representativeness: large vs. small suppliers, 2003.

\begin{tabular}{|c|c|c|c|c|}
\hline & \multicolumn{2}{|c|}{2003 complete sample } & \multicolumn{2}{|c|}{ Continuing Sample 2003} \\
\hline & $\begin{array}{c}\text { Small } \\
\text { suppliers }\end{array}$ & $\begin{array}{c}\text { Large } \\
\text { suppliers }\end{array}$ & $\begin{array}{c}\text { Small } \\
\text { suppliers }\end{array}$ & $\begin{array}{c}\text { Large } \\
\text { suppliers }\end{array}$ \\
\hline Number of suppliers & 1476 & 708 & 540 & 217 \\
\hline$\%$ of the suppliers & $67.58 \%$ & $32.42 \%$ & $71.33 \%$ & $28.67 \%$ \\
\hline$\%$ of total employment & $9.34 \%$ & $90.66 \%$ & $13.34 \%$ & $86.66 \%$ \\
\hline$\%$ of total sales & $6.92 \%$ & $93.08 \%$ & $11.46 \%$ & $88.54 \%$ \\
\hline$\%$ of total R\&D & $3.91 \%$ & $96.09 \%$ & $4.68 \%$ & $95.32 \%$ \\
\hline
\end{tabular}

For the small suppliers' size group, Table 2 shows that although R\&D intensity is lower in our sample than in the complete sample, other relevant characteristics such as the proportion of $R \& D /$ non $R \& D$ suppliers, supplier size or the share of $R \& D$ suppliers on total sales and employment are similar in both samples.

Table 2: Sample representativeness: R\&D suppliers vs. non R\&D suppliers, 2003

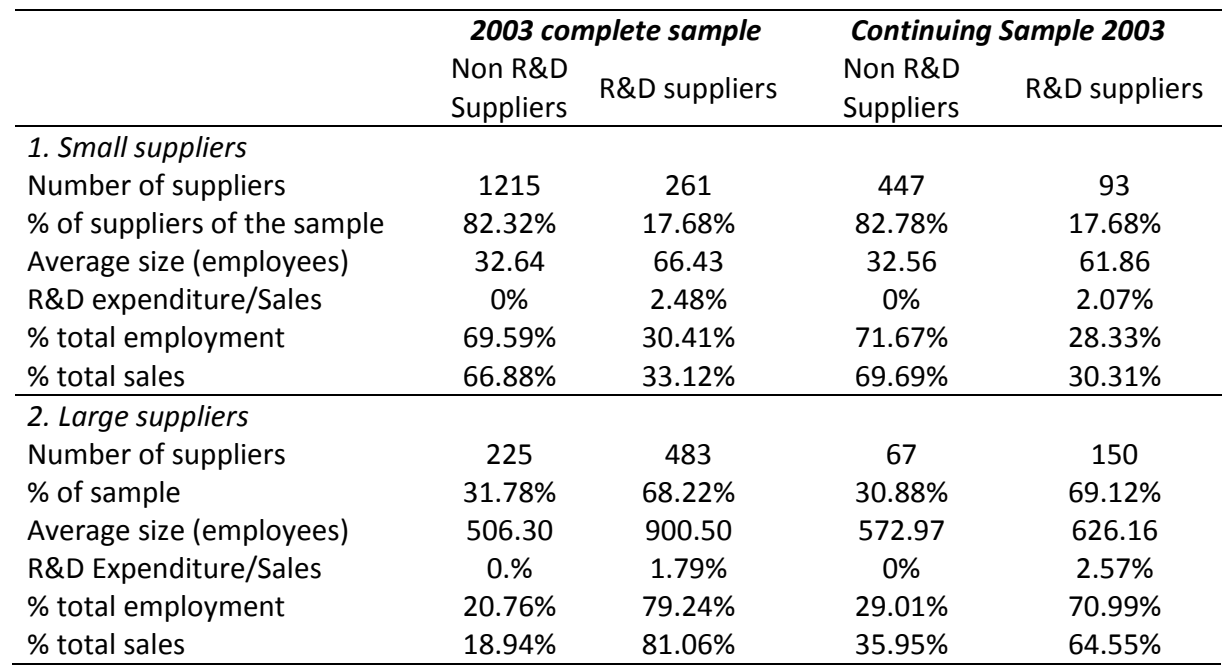


As for the large suppliers' size group, the proportion of R\&D/non R\&D suppliers is similar in both groups. However, R\&D intensity is higher in our continuing sample than in the complete sample and the participation of R\&D suppliers in total employment and sales is lower in our sample than in the complete one. Furthermore, R\&D suppliers in our continuing sample are substantially smaller than in the complete one.

These differences between the complete sample and our continuing sample mean that we could be not estimating the true probability of performing R\&D. However, we believe that the resemblances between our sample and the complete one still make valid our analysis.

We show in Table 3 the R\&D characteristics of our sample for the period 2003 2013 by size group.

\section{Table 3: R\&D characteristics}

\begin{tabular}{|c|c|c|c|c|c|c|c|c|c|c|c|}
\hline & 2003 & 2004 & 2005 & 2006 & 2007 & 2008 & 2009 & 2010 & 2011 & 2012 & 2013 \\
\hline \multicolumn{12}{|l|}{ 1. Small suppliers } \\
\hline $\begin{array}{l}\text { Number of R\&D } \\
\text { suppliers }\end{array}$ & 93 & 114 & 113 & 125 & 116 & 114 & 127 & 110 & 122 & 125 & 122 \\
\hline $\begin{array}{l}\text { Number of Non- } \\
\text { R\&D suppliers }\end{array}$ & 447 & 430 & 451 & 455 & 457 & 458 & 448 & 454 & 441 & 441 & 439 \\
\hline$\%$ of R\&D suppliers & $17.22 \%$ & $20.96 \%$ & $20.04 \%$ & $21.55 \%$ & $20.24 \%$ & $19.93 \%$ & $22.09 \%$ & $19.50 \%$ & $21.67 \%$ & $22.08 \%$ & $21.75 \%$ \\
\hline Total Sales & 265 & 278 & 305 & 357 & 371 & 387 & 441 & 440 & 464 & 497 & 463 \\
\hline $\begin{array}{l}\text { Total R\&D } \\
\text { Expenditure }\end{array}$ & 1,676 & 1,616 & 2,041 & 2,367 & 2,265 & 2,733 & 3,245 & 2,371 & 2,231 & 3,187 & 3,160 \\
\hline R\&D Exp/Sales (\%) & $0.63 \%$ & $0.58 \%$ & $0.66 \%$ & $0.65 \%$ & $0.60 \%$ & $0.69 \%$ & $0.71 \%$ & $0.52 \%$ & $0.46 \%$ & $0.61 \%$ & $0.66 \%$ \\
\hline \multicolumn{12}{|l|}{ 2. Large suppliers } \\
\hline $\begin{array}{l}\text { Number of R\&D } \\
\text { suppliers }\end{array}$ & 150 & 143 & 128 & 122 & 131 & 126 & 129 & 141 & 153 & 153 & 153 \\
\hline $\begin{array}{l}\text { Number of Non- } \\
\text { R\&D suppliers }\end{array}$ & 67 & 70 & 65 & 53 & 53 & 59 & 53 & 52 & 41 & 38 & 43 \\
\hline$\%$ of R\&D suppliers & $69.12 \%$ & $67.14 \%$ & $66.32 \%$ & $68.93 \%$ & $71.20 \%$ & $68.11 \%$ & $70.88 \%$ & $73.06 \%$ & $78.87 \%$ & $80.10 \%$ & $78.06 \%$ \\
\hline Total Sales & 2,051 & 2,105 & 2,074 & 1,924 & 2,272 & 2,508 & 2,492 & 2,736 & 2,932 & 3,126 & 3,410 \\
\hline $\begin{array}{l}\text { Total R\&D } \\
\text { Expenditure }\end{array}$ & 34,132 & 28,970 & 35,259 & 60,324 & 68,082 & 53,813 & 59,686 & 49,792 & 63,466 & 75,389 & 87,753 \\
\hline R\&D Exp/Sales (\%) & $1.66 \%$ & $1.40 \%$ & $1.73 \%$ & $3.19 \%$ & $3.05 \%$ & $2.16 \%$ & $2.43 \%$ & $1.83 \%$ & $2.24 \%$ & $2.55 \%$ & $2.69 \%$ \\
\hline
\end{tabular}

Notes: Total sales are in billions and Total R\&D expenditure are in millions. The denominator or the ratio R\&D Exp./Sales includes sales of both R\&D and Non R\&D suppliers.

The proportion of R\&D suppliers increased for both groups along the period, though such proportion always remained much higher for large suppliers. Thus, the R\&D suppliers' proportion in small suppliers slightly rose from $17.22 \%$ to $21.75 \%$ and in large suppliers from $69.12 \%$ to $78.06 \%$. At the same time, R\&D intensity (defined as R\&D expenditure over sales) grew much faster in large suppliers than in small ones: whereas for small suppliers' R\&D intensity just increased $4.76 \%$ (from $0.63 \%$ to $0.66 \%$ ), for large suppliers it increased $62.05 \%$ (from $1.66 \%$ to $2.69 \%$ ). This can be explained because large suppliers' annual growth rate of R\&D expenditure almost doubled the annual growth rate of sales $(9.44 \%$ and $5.08 \%$, respectively), 
while in the small ones the annual growth rate of R\&D expenditure was around one point higher than the sales rate $(6.34 \%$ and $5.59 \%$, respectively). Hence, whilst in 2003 the R\&D intensity of large suppliers is 2.6 times that of small ones $(1.66 \%$ and $0.63 \%$, respectively), in 2013 it is four times larger (2.69\% versus $0.66 \%$ for small suppliers).

\subsection{Flows in and out of R\&D activities}

To evaluate the importance of the flows in and out of R\&D activities, we analyze the transition rates in our sample (Table 4). In this table, each row describes the transition from the R\&D status in the first column to the status in the second column. Each one of the entries in these rows is the proportion of suppliers in each of the year- $t$ status that choose each of the two possible status in year $t+1$. As in former tables the top panel applies to small suppliers and the bottom panel to large suppliers. Additionally, Figure 1 shows the number of R\&D and non-R\&D suppliers as well as the entry rate (proportion of non-R\&D suppliers in $t$ that perform R\&D in $t+1$ ) and the exit rate (proportion of R\&D suppliers in $t$ that do not perform $R \& D$ in $t+1$ ) for each year of the sampling period.

\section{Table 4: Suppliers transition rates in the R\&D market 2003 - 2013}

\begin{tabular}{|c|c|c|c|c|c|c|c|c|c|c|c|c|}
\hline $\begin{array}{l}\text { Year } t \\
\text { status }\end{array}$ & $\begin{array}{l}\text { Year } t+1 \\
\text { status }\end{array}$ & $\begin{array}{c}2003- \\
04\end{array}$ & $\begin{array}{c}2004- \\
05\end{array}$ & $\begin{array}{c}2005- \\
06\end{array}$ & $\begin{array}{c}2006- \\
07\end{array}$ & $\begin{array}{c}2007- \\
08\end{array}$ & $\begin{array}{c}2008- \\
09\end{array}$ & $\begin{array}{c}2009- \\
10\end{array}$ & $\begin{array}{c}2010- \\
11\end{array}$ & $\begin{array}{c}2011- \\
12\end{array}$ & $\begin{array}{c}2012- \\
13\end{array}$ & $\begin{array}{c}\text { Average } \\
2003- \\
2013\end{array}$ \\
\hline \multicolumn{13}{|c|}{ 1. Small suppliers } \\
\hline \multirow[t]{2}{*}{ Non R\&D } & Non R\&D & 0.912 & 0.955 & 0.940 & 0.944 & 0.954 & 0.941 & 0.953 & 0.926 & 0.933 & 0.943 & 0.940 \\
\hline & $R \& D$ & 0.087 & 0.044 & 0.059 & 0.055 & 0.045 & 0.059 & 0.046 & 0.073 & 0.066 & 0.057 & 0.059 \\
\hline \multirow[t]{2}{*}{$R \& D$} & Non R\&D & 0.193 & 0.245 & 0.209 & 0.275 & 0.233 & 0.131 & 0.241 & 0.171 & 0.235 & 0.176 & 0.211 \\
\hline & $R \& D$ & 0.806 & 0.754 & 0.790 & 0.724 & 0.767 & 0.868 & 0.758 & 0.828 & 0.764 & 0.823 & 0.788 \\
\hline \multicolumn{13}{|c|}{ 2. Large suppliers } \\
\hline \multirow[t]{2}{*}{ Non R\&D } & Non R\&D & 0.806 & 0.918 & 0.876 & 0.784 & 0.917 & 0.802 & 0.863 & 0.788 & 0.868 & 0.879 & 0.850 \\
\hline & $R \& D$ & 0.194 & 0.081 & 0.123 & 0.215 & 0.082 & 0.197 & 0.137 & 0.211 & 0.131 & 0.120 & 0.149 \\
\hline \multirow[t]{2}{*}{$R \& D$} & Non R\&D & 0.133 & 0.090 & 0.058 & 0.079 & 0.062 & 0.085 & 0.055 & 0.034 & 0.032 & 0.081 & 0.071 \\
\hline & $R \& D$ & 0.866 & 0.909 & 0.941 & 0.920 & 0.937 & 0.914 & 0.944 & 0.965 & 0.967 & 0.918 & 0.928 \\
\hline
\end{tabular}

Note: Each one of the entries in the table is the proportion of suppliers in each of the year $t$ status that chooses each of the two possible status in year $t+1$.

Both Figure 1 and the second and third rows of each panel of Table 4 (transitions from non R\&D to R\&D and from R\&D to non R\&D), that show the entry and exit rates from R\&D activities, uncover that carrying out $R \& D$ one year does not mean necessarily permanence in this activity. For small suppliers, the average exit rate exceeds the average entry rate $(21.1 \%$ and $5.9 \%$, respectively), suggesting a high rate of turnover. For large suppliers the average entry rate more than doubles average exit rate ( $15 \%$ and $7 \%$, respectively). Thus after a decrease in the number of large suppliers performing R\&D in the year 2003, the number of large suppliers that perform R\&D steadily increases until 2013. These points out a trend of incorporation to $R \& D$ activities and of permanence in this $R \& D$ status: it is very likely that once a large supplier starts performing R\&D it keeps doing it. As a result 
of these entry and exit rates there was a net gain of 32 R\&D suppliers ( 29 of them were classified as small firms in 2003 and 3 as large ones). Notwithstanding, the proportion of small suppliers performing R\&D is still very small if compared with that of the large suppliers (whereas in 2013, 70.54\% of the large suppliers performed R\&D, this percentage for the small suppliers was $22.59 \%$ ).

a. Small suppliers

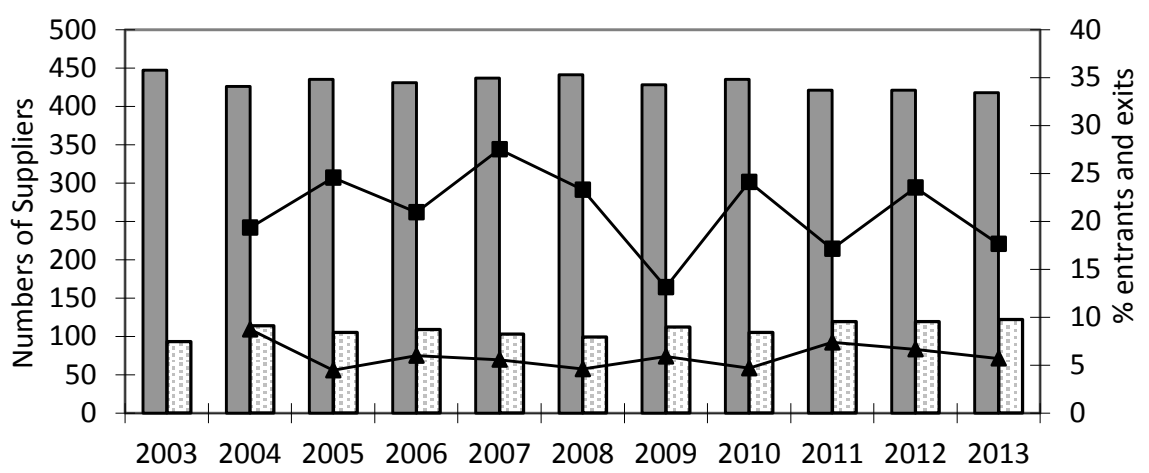

$\square$ Non R\&D $\square$ R\&D —Entrants $\rightarrow$ Exits

b. Large suppliers

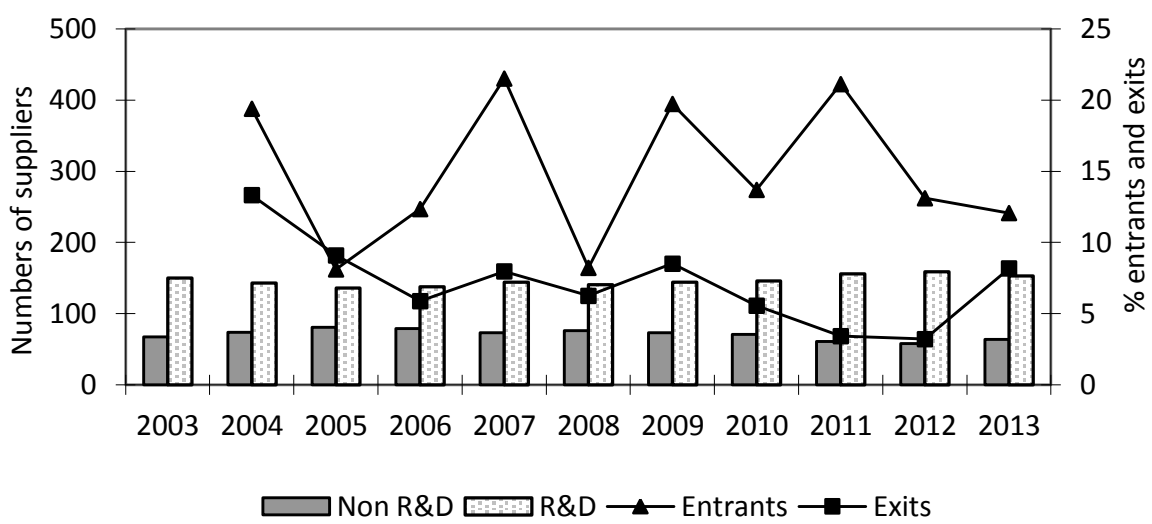

Figure 1: Transitions in and out of R\&D activities 
Simultaneously to this R\&D activities substantial entry and exit, there is an important degree of persistence in the status of an individual supplier: $52.53 \%$ of large suppliers and $61.11 \%$ of small suppliers never change status. Columns 1 and 2 of Table 5 show the proportion of R\&D suppliers and non-R\&D suppliers in 2003 that had the same status in one of the subsequent 10 years.

\section{Table 5: Persistence of R\&D activities (and Non-R\&D)- Proportion of 2004 suppliers with the same export status.}

\begin{tabular}{ccccc}
\hline & $\begin{array}{c}(1) \\
\text { R\&D suppliers } \\
\text { Actual }\end{array}$ & $\begin{array}{c}(2) \\
\text { Non-R\&D suppliers } \\
\text { Actual }\end{array}$ & $\begin{array}{c}(3) \\
\text { R\&D suppliers } \\
\text { Expected }\end{array}$ & $\begin{array}{c}(4) \\
\text { Non-R\&D suppliers } \\
\text { Expected }\end{array}$ \\
\hline 1. Small suppliers & & & & \\
2004 & $80.65 \%$ & $91.28 \%$ & $80.65 \%$ & $91.28 \%$ \\
2005 & $73.11 \%$ & $91.72 \%$ & $60.84 \%$ & $87.21 \%$ \\
2006 & $69.89 \%$ & $90.16 \%$ & $48.10 \%$ & $81.99 \%$ \\
2007 & $63.44 \%$ & $90.16 \%$ & $34.86 \%$ & $77.43 \%$ \\
2008 & $61.29 \%$ & $90.60 \%$ & $26.74 \%$ & $73.88 \%$ \\
2009 & $63.44 \%$ & $88.14 \%$ & $23.23 \%$ & $69.52 \%$ \\
2010 & $60.21 \%$ & $89.04 \%$ & $17.63 \%$ & $66.27 \%$ \\
2011 & $63.44 \%$ & $86.58 \%$ & $14.61 \%$ & $61.40 \%$ \\
2012 & $63.44 \%$ & $86.58 \%$ & $11.17 \%$ & $57.31 \%$ \\
2013 & $66.67 \%$ & $86.58 \%$ & $9.20 \%$ & $54.05 \%$ \\
\hline 2. Large suppliers & & & & \\
2004 & $86.67 \%$ & $80.60 \%$ & $86.67 \%$ & $80.60 \%$ \\
2005 & $80.67 \%$ & $77.62 \%$ & $78.79 \%$ & $74.06 \%$ \\
2006 & $80.67 \%$ & $74.63 \%$ & $74.16 \%$ & $64.92 \%$ \\
2007 & $81.33 \%$ & $67.16 \%$ & $68.25 \%$ & $50.95 \%$ \\
2008 & $78.00 \%$ & $64.18 \%$ & $63.98 \%$ & $46.76 \%$ \\
2009 & $80.00 \%$ & $64.18 \%$ & $58.54 \%$ & $37.53 \%$ \\
2010 & $82.00 \%$ & $65.67 \%$ & $55.28 \%$ & $32.39 \%$ \\
2011 & $84.00 \%$ & $55.22 \%$ & $53.39 \%$ & $25.54 \%$ \\
2012 & $84.00 \%$ & $50.74 \%$ & $51.68 \%$ & $22.19 \%$ \\
2013 & $81.33 \%$ & $53.73 \%$ & $47.45 \%$ & $19.52 \%$ \\
\hline
\end{tabular}

Note: The figures in columns (1) and (2) represent the percentage of R\&D (non R\&D) suppliers that were also $R \& D$ (non-R\&D) in the listed year, i.e. 62.65 of the small suppliers that carry out R\&D in 2004 also did it in 2010. The figures in columns (3) and (4) show the expected percentages if entering and exiting suppliers were chosen randomly with annual transition rates given by the data. Let us an example how we calculate columns (3) and (4) figures. In 2004 the number of R\&D suppliers in the small suppliers group was 83 (see Table 4) and from Table 5 we know that the exit rate for the small suppliers group for the $2004-2005$ period is $20.48 \%$. Therefore, the expected number of R\&D suppliers in 2005 is obtained as $83 *(1-0.2048)=66$, and 66 is approximately $79.51 \%$ of 83 .

The percentage of suppliers in the small suppliers group that performed R\&D in 2003 and was also performing R\&D in 2008 is slightly over $61 \%$ and five years later this percentage is even larger $66.7 \%$. In the large suppliers group persistence is even more intense as $78 \%$ of the suppliers performing R\&D in 2003 also carried out $R \& D$ in 2008 and five years later this percentage is even larger, 81.3\%. Whereas for the large suppliers group persistence in the non-R\&D status, though important, is 
not as intense as in the R\&D status, for the small suppliers group persistence in the non-R\&D status is even stronger than in the R\&D status. From the large suppliers that did not perform R\&D in 2003 64\% did not do it five years later and $53.7 \%$ did not perform R\&D in 2013. Among the small suppliers, persistence in the non-R\&D status is even higher, as the aforementioned percentages raise to almost $91 \%$ and $86.6 \%$, respectively. This lower rate of persistence for large suppliers in the non$R \& D$ status confirms the trend of incorporation to the $R \& D$ activities detected above.

Columns 3 and 4 report the predicted rates of persistence in each of the two status. These are calculated using the annual transition rates given by the data and reported in Table 4. Regardless the size group and all over the sampling period, predicted persistence are lower than sample actual persistence. Hence, we can extract two conclusions: first, that the probability of performing R\&D is higher for suppliers that have performed R\&D before, i.e. there is a high rate of reentry by former R\&D suppliers; second and analogously, suppliers performing R\&D with a non-R\&D past have a higher probability of quitting their $R \& D$ activities. The aim of this paper is to disentangle whether this status persistence results from supplier attributes or the existence of sunk costs associated to R\&D activities.

After having detected heterogeneity of entry and exit rates across size groups, we analyze if there exists heterogeneity across suppliers. Figure 2, shows average annual entry and exit rates for the 20 suppliers of the overall sample of suppliers.

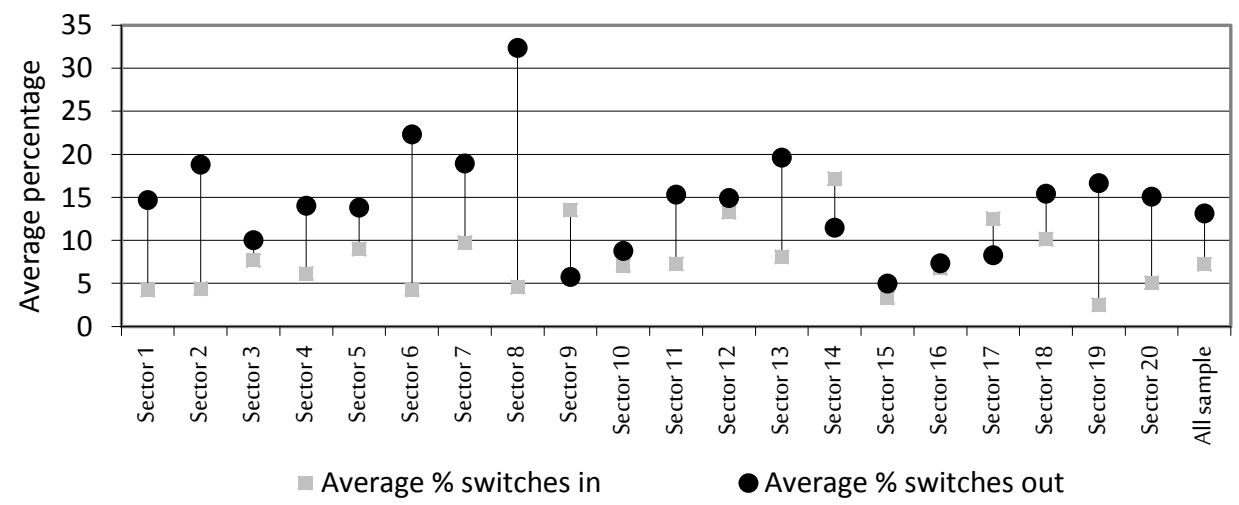

Figure 2: Suppliers switching in and out of R\&D activities

Note: The average annual entry rates (into the R\&D market) and exit rates (out of the R\&D market) are represented by the squares and the circles respectively.

While most of the suppliers' exhibit turnover patterns that are similar to the overall sample, some suppliers such as office machines show lower entry and exit rates that the average and others such as printing and printing stuff show exceptionally high exit rates. Furthermore, only the metallic products and motors and cars suppliers show entry rates that are lower than exit rates. These results suggest that sunk costs of entry and exit as well as supplier characteristics must be important 
determinants of the decision to perform R\&D activities. We propose next an econometric model to analyze the role of supplier characteristics and sunk costs in shaping the suppliers' R\&D decision.

\section{Modelling the R\&D decision.}

We follow Roberts and Vuong (2013) in modelling the decision to invest in R\&D by a rational, profit-maximizing supplier. The supplier considers expected profits today and in the future from the decision to perform R\&D, net of entry and exit sunk costs. In each period t the variation in gross profits adjusted for sunk costs is given by the following expression

$$
\hat{\pi}_{i t}=y_{i t}\left[\pi_{i t}\left(p_{t}, s_{i t}\right)-F_{i t}^{0}\left(1-y_{i, t-1}\right)-\sum_{j=2}^{J_{i}}\left(F_{i t}^{j}-F_{i t}^{0}\right) \tilde{y}_{i, t-j}\right]-G_{i t} y_{i, t-1}\left(1-y_{i t}\right)
$$

were the indicator variable $y_{i t}$ takes the value of 1 if the supplier performs $R \& D$ in period $\mathrm{t}$ and 0 otherwise. $\pi_{i t}$ is the current increment to gross profits associated with the decision of performing R\&D; supplier-specific characteristics, market characteristics and spillovers (supplier, regional and local) are included in the vector $S_{i t}$; while other factors such as credit market conditions, R\&D policy and macro conditions are included in $p_{t} . J_{i}$ is the age of the firm and $\tilde{\boldsymbol{y}}_{i, t-j}=\left(\boldsymbol{y}_{i, t-j} \prod_{k=1}^{j-1}\left(\mathbf{1}-\boldsymbol{y}_{i, t-k}\right)\right)$ summarizes supplier $i$ recent R\&D experience and takes the value of 1 if the last period that supplier $i$ performed R\&D was period $t-j$ and 0 otherwise. To account for sunk costs we make the following assumptions. First, a supplier that has never done R\&D would face an entry cost of $F_{i t}^{\mathrm{O}}$ and would earn the first year doing R\&D, $\pi_{i t}\left(p_{i t}, s_{i t}\right)-F_{i t}^{\mathrm{O}}$. Second, a supplier that did R\&D in the previous period, i.e. if $y_{i, t-1}=1$, does not have to pay the entry cost in $t$ and would earn $\pi_{i t}\left(p_{t}, s_{i t}\right)$, but if this supplier decides to exit it would incur in an exit cost represented by $-G_{i t}$. Finally, we also consider suppliers that abandon R\&D activities in previous periods $(t-j$ with $j \geq 2)$ and decide to re-start R\&D again. In this case, we will assume that the supplier faces a re-entry cost of $F_{i t}{ }^{j}$, which would leave the supplier earnings, $\pi_{i t}\left(p_{i}, s_{i t}\right)-F_{i t}^{j}$. The $j$ subscript indicates that re-entry costs depend on the length a supplier has been away from R\&D activities. This time-dependence could reflect the depreciation of knowledge and experience accumulated during the R\&D period or the increasing cost of updating the supplier to the "changing" R\&D activities. The $i$ and $t$ subscripts allow for sunk costs to vary both across suppliers (with differences in size, experience, ownership and other characteristics) and time (changes in financial or credit market conditions, R\&D policies that affect choices of suppliers, etc.). 
We assume that in period $t$ managers plan the supplier R\&D participation sequence that maximises the expected current and discounted future profits net of sunk costs. This maximised payoff is,

$$
V_{i t}=\max _{\left|y_{i s}^{\infty}\right|_{s=t}^{\infty}} E_{t}\left(\sum_{s=t}^{\infty} \delta^{s-t} \hat{\pi}_{i s}\right)
$$

Where $E_{t}$ is an expectations operator conditioned on the set of supplier information at time $t$ and $\delta$ is a time discount rate. Supplier $i$ chooses the current $y_{i t}$ value that satisfies the Bellman's equation:

$$
V_{i t}=\max _{y_{i t}} \hat{\pi}_{i t}+\delta E_{t}\left[\left.V_{i, t+1}|| y_{i t-j}\right|_{j=0} ^{J_{i}}\right]
$$

Incorporating entry and exit sunk costs in a multi-period decision problem provides a means for present and past R\&D decisions by the supplier to influence future decisions.

A supplier that decides performing R\&D in t gets as expected present value of payoffs

$$
\pi_{i t}+\delta E_{t}\left(\left.V_{i, t+1}\left|y_{i t}=1,\right| y_{i t-j}\right|_{j=1} ^{J_{i}}\right)-F_{i t}^{0}\left(1-y_{i, t-1}\right)-\sum_{j=2}^{J_{i}}\left(F_{i t}^{j}-F_{i t}^{0}\right) \tilde{y}_{i, t-j}
$$

and one that decides not doing it

$$
\delta E_{t}\left(\left.V_{i, t+1}\left|y_{i t}=0,\right| y_{i t-j}\right|_{j=1} ^{J_{i}}\right)-G_{i t} y_{i, t-1}
$$

The ith supplier will decide to do R\&D during period $t$ whenever (4) minus (5) is positive, that is when

$\pi_{i t}+\delta\left[E_{t}\left(V_{i, t+1} \mid y_{i t}=1\right)-E_{t}\left(V_{i, t+1} \mid y_{i t}=0\right)\right]-F_{i t}^{0}+\left(F_{i t}^{0}+G_{i t}\right) y_{i, t-1}-\sum_{j=2}^{J_{i}}\left(F_{i t}^{j}-F_{i t}^{0}\right) \tilde{y}_{i, t-j} \geq 0$

The empirical specification to model a supplier decision to do R\&D is derived from the participation condition given by equation (6). Defining the latent variable $\pi_{i t}^{*}$ as current gross operating profits plus the discounted expected future return from being an R\&D supplier in year $t$,

$$
\pi_{i t}^{*}=\pi_{i t}+\delta\left[E_{t}\left(V_{i, t+1} \mid y_{i t}=1\right)-E_{t}\left(V_{i, t+1} \mid y_{i t}=0\right)\right]
$$

$R \& D$ participation is then given by the following dynamic discrete choice process:

$$
y_{i t}=\left\{\begin{array}{ccc}
1 & \text { if } & \pi_{i t}^{*}-F_{i t}^{0}+\left(F_{i t}^{0}+G_{i t}\right) y_{i, t-1}-\sum_{j=2}^{J_{i}}\left(F_{i t}^{j}-F_{i t}^{0}\right) \tilde{y}_{i, t-j} \geq 0 \\
0 & \text { otherwise }
\end{array}\right.
$$

Following Roberts and Vuong (2003), we approximate $\pi_{i t}^{*}-F_{i t}^{\mathrm{O}}$ as a reduced-form expression in exogenous supplier characteristics and spillovers $\left(X_{\mathrm{it}}\right)$, macro conditions $\left(\mu_{t}\right)$, and noise $\left(\varepsilon_{i t}\right)$. Supplier characteristics, spillovers and macro conditions are assumed to be observable to the supplier in period $t$,

$$
\pi_{i t}^{*}-F_{i t}^{\mathrm{O}}=\mu_{i}+\beta X_{i t}+\varepsilon_{i t}
$$


Finally, we also consider some identifying assumptions (also used in Roberts and Tybout, 1997) in relation to sunk entry, re-entry and exit costs. First, we assume that sunk costs do not vary across time. Second, we suppose that sunk entry costs for suppliers that have not performed R\&D for at least $J$ years are the same, $F_{i}^{\mathrm{O}}=F^{\mathrm{O}}$, and that all suppliers that have not performed R\&D for $j<J$ years incur in the same re-entry sunk costs, $F_{i}^{j}=F^{j}$. Finally, we consider that all suppliers currently doing $\mathrm{R} \& \mathrm{D}$ have the same exit cost $G_{i}=G$. Using the above assumptions, re-defining $F^{0}-F^{j}=\gamma^{j}$ for $j=2, \ldots, J$ and $F^{0}+G=\gamma^{0}$, and substituting equation (9) into (8), we have the estimation equation used in our empirical exercise,

$$
y_{i t}= \begin{cases}1 & \text { if } \mu_{t}+\beta X_{i t}+\gamma^{\circ} y_{i, t-1}+\sum_{j=2}^{J} \gamma^{j} \tilde{y}_{i, t-j}+\varepsilon_{i t} \geq 0 \\ 0 & \text { otherwise }\end{cases}
$$

From the last expression one can note that the participation decision does not depend on the supplier R\&D background if sunk costs are zero. This allows testing for the importance of sunk costs in the decision to do R\&D by testing whether $\gamma^{0}$ and the values of $\gamma^{j}$, for $j=2, \ldots, J$, are jointly equal to zero. If they are significantly different from zero then it is possible to analyse the rate of depreciation of $R \& D$ experience and accumulated knowledge in R\&D activities by looking at these coefficients individually.

\section{R\&D efficiency}

R\&D efficiency is measured as the ratio of a supplier's production over its optimal level. The optimal behaviour, the technically efficient result of the production process, is represented by a production function, a frontier, which shows the maximum level of output a supplier could achieve, given the technology and a given level of inputs. The first step of this approach is to estimate the practice frontier obtained from the sample information, using their best observations. If a supplier produces this optimal level of output, it is technically efficient and it will be on the frontier. If a supplier produces less than is technically feasible, given both, the technology and a level of inputs, it is efficient and we can measure the degree of technical efficiency as the distance from each individual observation and a corresponding point on the frontier.

R\&D efficiency is estimated from the stochastic frontier and simultaneously explained by a set of variables representative of the suppliers' characteristics. This approach avoids the inconsistency problems of the two-stage approach used in previous empirical works when analyzing the R\&D efficiency determinants. The model can be expressed as:

$$
Y_{i t}=f\left(X_{i t} ; \beta\right) \exp \left(v_{i t}-u_{i t}\right)
$$


Where $\mathrm{i}$ indicates suppliers and $t$ represents the period, $X$ is the set of inputs; $\beta$ is the set of parameters, $v_{i t}$ is a two-sided term representing the random error, assumed to be $\mathrm{N}\left(0, \sigma_{\mathrm{v}}{ }^{2}\right) ; u_{i t}$ is a non-negative random variable representing the efficiency, which is assumed to be distributed independently and obtained by truncation at zero of $N\left(0, \sigma_{u}{ }^{2}\right)$. We introduce some explanatory variables to explain efficiency assuming that

$$
\sigma_{u i t}^{2}=\delta_{0}+\sum_{j=1}^{M} \delta_{j} Z_{i j t}
$$

Where $Z_{i j t}$ is a $(M \times 1)$ vector of variables that may have effects over supplier efficiency, $\delta_{\mathrm{j}}$ is a $(1 \mathrm{xM})$ vector of parameters to be estimated. We also control for heteroscedasticity, allowing the noise term to reflect differences between suppliers related to size. Given that technical efficiency is the ratio of observed production over the maximum technical output obtainable for a supplier (when there is no inefficiency), the efficiency index (TE) of firm $i$ in year $t$ could be written as:

$$
T E=\frac{f\left(X_{i t} ; \beta\right) \exp \left(v_{i t}-u_{i t}\right)}{f\left(X_{i t} ; \beta\right) \exp \left(v_{i t}\right)}=\exp \left(-u_{i t}\right)
$$

The efficiency scores obtained from expression (3) take value one when the firm is efficient, and less than one otherwise.

We estimate a stochastic translog production function adding a term of efficiency, whose variance is the function of a set of efficiency determinants:

$$
\begin{gathered}
\ln Y_{i t}=\beta_{0}+\sum_{j} \beta_{j} \ln x_{i j t}+\frac{1}{2} \sum_{j} \sum_{k} \beta_{j k} \ln x_{i j t} \ln x_{i k t}+\sum_{j} \varphi_{j} S_{i j}+v_{i t}-u_{i t} \\
\sigma_{u i t}^{2}=\delta_{\mathrm{O}}+\sum_{j=1}^{M} \delta_{j} Z_{i j t}
\end{gathered}
$$

The variables used for estimation of the production frontier are the value-added, such as the output variable, and the number of employees in the supplier, capital stock and trend, as input variables $\left(x_{i t}\right)$, and the industrial sector dummies $\left(S_{i}\right)$ and two dummies that indicate if suppliers have undertaken process (INPR) or product innovation (INP). Here we present a more precise definition of the variables used for estimation and the definition of the efficiency determinants considered.

\subsection{Variables of R\& D Efficiency of Stochastic Frontier estimations:}

VA: The value added in real terms. This is a dependent variable.

CAPITAL STOCK (K): Inventory value of fixed assets excluding grounds and buildings.

L: Total employment by firm.

$\mathrm{T}$ : This is the time trend. 
INP: dummy that takes value 1 if there is product innovation and 0 otherwise. INPR: dummy that takes value 1 if there is process innovation and 0 otherwise.

Sector classification: There are seven dummy variables that take value one when the firm belongs to the corresponding sector of activity; otherwise this value is zero.

SEC1: Meat and manufacturing of meat; food industry and tobacco drinks; textiles, clothing and shoes; leather, shoes and derivatives. SEC2: Wood and derivatives, paper and derivatives.

SEC3: Chemical products; cork and plastic; non-metallic mineral products.

SEC4: Basic metal products; manufactured metal products; industrial equipment.

SEC5: Office machinery and others; electrical materials.

SEC6: Cars and engines; other material transport.

SEC7: Other manufactured products.

\subsection{Determinants of R\& D efficiency}

PROPORTION OF TEMPORARY: This is the proportion of temporary workers on total employment

GROSS INVESTMENT OVER CAPITAL: This is the ratio between gross investments over capital by firm.

INNOVATION INVESTMENT OVER CAPITAL: This is the ratio between gross investments over capital by firm.

R\&D INTENSITY: This is the ratio between R\&D expenditures over Value added

LEVERAGE: This is the ratio between external total funds over added value.

SIZE: There are six dummy variables that take value one when the firm belongs to the corresponding interval of workers, zero otherwise:

- SIZE 1: Firms with no more than twenty workers.

- SIZE 2: from 21 up to 50.

- SIZE 3: from 51 up to 100.

- SIZE 4: from 101 up to 200.

- SIZE 5: from 201 up to 500.

- SIZE 6: Firms with a number of workers higher than 500.

From the frontier approach, we obtain the measure of a supplier's R\&D efficiency compared with the best observations of the sample. The value of the estimates allows us to explain the differences in the efficiency effects among the suppliers. As 
technological and market conditions can vary over sectors, we have included sector dummy variables in the production function in order to be able to control it. The maximum-likelihood estimates of the production frontier parameters, defined in equation (14), given the specification for the efficiency effects, defined in equation (15), are presented in Table 6.

\section{Table 6: Stochastic Frontier Analysis}

\begin{tabular}{|l|c|c|c|c|}
\hline Translog Production function estimates.Variables & & $\begin{array}{c}\text { Coefficien } \\
\mathrm{t}\end{array}$ & $\begin{array}{c}\text { Standard- } \\
\text { Error }\end{array}$ & T- Student \\
\hline Constant & $\beta_{0}$ & 5.883 & 0.000 & 41.302 \\
\hline $\mathrm{T}$ & $\beta_{1}$ & 0.146 & 0.000 & 7.971 \\
\hline $\mathrm{L}$ & $\beta_{2}$ & 1.074 & 0.000 & 21.592 \\
\hline $\mathrm{K}$ & $\beta_{3}$ & -0.110 & 0.000 & -5.508 \\
\hline $\mathrm{K}^{2}$ & $\beta_{11}$ & 0.042 & 0.000 & 23.894 \\
\hline $\mathrm{L}^{2}$ & $\beta_{22}$ & 0.076 & 0.000 & 11.661 \\
\hline $\mathrm{T}^{2}$ & $\beta_{33}$ & -0.013 & 0.000 & -6.824 \\
\hline KxL & $\beta_{12}$ & -0.195 & 0.000 & -14.939 \\
\hline LxT & $\beta_{13}$ & 0.025 & 0.000 & 6.348 \\
\hline KxT & $\beta_{23}$ & -0.019 & 0.000 & -7.305 \\
\hline INP & $\beta_{4}$ & 0.025 & 0.093 & 1.681 \\
\hline INPR & $\beta_{5}$ & 0.034 & 0.003 & 2.980 \\
\hline Wood and derivatives, paper and derivatives & $\varphi_{1}$ & -0.066 & 0.008 & -2.651 \\
\hline Chemical products; non-metallic mineral products & $\varphi_{2}$ & -0.192 & 0.000 & -4.301 \\
\hline Basic metal products; industrial equipment & $\varphi_{3}$ & 0.044 & 0.123 & 1.541 \\
\hline Office machinery and others; electric materials & $\varphi_{4}$ & 0.095 & 0.000 & 3.754 \\
\hline Cars and engines; other material transport & $\varphi_{5}$ & 0.177 & 0.000 & 5.167 \\
\hline Others manufactured products. & $\varphi_{6}$ & 0.053 & 0.193 & 1.301 \\
\hline Efficiency model & \multicolumn{5}{|l|}{} \\
\hline Gross investment over capital & $\delta_{1}$ & -1.643 & 0.000 & -7.197 \\
\hline R\&D intensity & $\delta_{2}$ & -0.186 & 0.000 & -4.818 \\
\hline External funds over VA & $\delta_{3}$ & 0.021 & 0.000 & 9.058 \\
\hline Temporary workers proportion & $\delta_{4}$ & 0.376 & 0.023 & 2.282 \\
\hline New products investment over capital & $\delta_{5}$ & -2.682 & 0.000 & -4.078 \\
\hline Size1: Up to 20 workers & $\delta_{7}$ & -0.917 & 0.000 & -6.473 \\
\hline Size2: From 21 to 50 & $\delta_{8}$ & -0.924 & 0.000 & -6.227 \\
\hline Size3: From 51 to 100 & $\delta_{9}$ & -1.008 & 0.000 & -7.488 \\
\hline Size4: From 101 to 200 & $\delta_{10}$ & -0.930 & 0.000 & -7.015 \\
\hline Size5: From 201 to 500 & $\delta_{11}$ & -0.800 & 0.000 & -5.719 \\
\hline Heteroscedasticity & $\Phi_{1}$ & 0.000 & 0.746 & 0.324 \\
\hline L & $\Phi_{2}$ & -0.033 & 0.227 & -1.209 \\
\hline INP & $\Phi_{3}$ & 0.009 & 0.644 & 0.462 \\
\hline INPR & & & & \\
\hline
\end{tabular}

We use the translog specification for the production function and we obtain the expected signs of the inputs estimates. We also obtain that both dummies representing suppliers' innovative activities have a positive and statistically 
significant coefficient. Respect to the R\&D efficiency determinants, our results show that R\&D efficiency tends to be larger for suppliers with a high ratio of external financial funds over total assets. As higher is the leverage more difficult is for suppliers to be close to the frontier. The ratio of temporary over total employment shows, also, a negative impact over R\&D efficiency. We find a negative and significant relationship between size and technical efficiency. Due to this effect of market selection, the surviving small suppliers that we observe may on average show a higher level of technical efficiency than the larger suppliers do. The R\&D intensity, affects positively the supplier's efficiency, that is, innovative suppliers tend to be closer to the frontier than those suppliers that do not perform $R \& D$ spending. We obtain the same significant effect for variables representing the degree of investment. These results allow us to conclude that the most innovative companies are closer to the efficient frontier than those that are not innovative. To sum up, the impact of the investment in R\&D over efficiency and consequently over production has been positive and statistically significant. Our results indicate that innovative suppliers produce more efficiently than non-innovative suppliers. This implies that all policies conducted to incentive this kind of investment will contribute to a productivity growth in the long run.

\section{Econometric issues}

Given that we are interested in isolating the effects of true state dependence (sunk costs hysteresis) in $R \& D$ activities (to the extent that $R \& D$ experience raises the risk of doing R\&D in the future), we control in our modelling and estimation for: (i) endogenous initial conditions, (ii) differences in observed and unobserved characteristics between suppliers ("heterogeneity") and (iii) serial correlation in the error terms. Observed persistence may be due to persistence of observable supplier characteristics, serial correlation of errors, true state dependence or permanent unobserved heterogeneity. In the last three cases we observe that for given observable characteristics firms choose an option more frequently when they have chosen it in the past. However, there is only true state dependence if previous choices affect the current one. In dynamic models if we do not control for permanent unobserved heterogeneity and serial correlation of errors the state dependence coefficients are seriously biased: one can get significant coefficients even when there is no state dependence and persistence is only due to permanent heterogeneity and/or serial correlation in the errors.

Thus, it is clear that to isolate the importance of sunk costs, it is critical that we control for all other sources of persistence in the R\&D status. Much of this task is accomplished by including the vector of observable supplier characteristics $X_{i t}$ in equation (10). However, it is highly probable that even after controlling for all the observed characteristics, there will still remain unobserved ones such as managerial ability, technology and other unobserved supplier effects which affect the decision to do R\&D by the firm. Since these characteristics are potentially permanent, or at least highly serially correlated and unobserved by the 
econometrician, they will induce persistence in R\&D behaviour, either in or out of that activity, and thus will cause us to overestimate the entry costs and experience effects. In practice this means that the error term in equation (10) $\left(\varepsilon_{i t}\right)$ can be thought of as comprising two components, a permanent supplier-specific element ( $\left.\alpha_{i}\right)$ and a transitory component $\left(u_{i t}\right)$, which captures other exogenous shocks. Hence, we allow in our specification, for two sources of serial correlation in $\varepsilon_{i t}$. One coming from dependence of $\operatorname{cov}\left(\varepsilon_{i t}, \varepsilon_{i t-1}\right)$ on the permanent component of the error, and another coming from serial correlation in transitory shocks to R\&D profits. Furthermore, we assume $\operatorname{cov}\left(X_{i t}, \varepsilon_{i t}\right)=\mathrm{O} \forall i, t$, and we normalize $\operatorname{Var}\left(\varepsilon_{i t}\right)=1$. If we use an estimator that ignores serial correlation, the model will incorrectly attribute this persistence in R\&D status to sunk costs.

There remains an additional problem. We observe a supplier R\&D status in years 1 through $T$, and our lag structure reaches back $J$ periods, so equation (10) can be used to model the R\&D decision in years $J+1$ through $T$. But values corresponding to the first $J$ years $\left(y_{i 1}, \ldots, y_{i}\right)$ cannot be treated as exogenous determinants of $y_{i t}$ because each depend on $\alpha_{i}$ and previous realizations of $u_{i t}$, both of which are correlated with $\varepsilon_{i t}$. Heckman (1981c) suggests dealing with this "initial-conditions" problem by using an approximate representation for $\boldsymbol{y}_{i t}$ when $t \leq J$ and allowing the disturbances for the first $J$ periods to be correlated with the disturbances in every other period. Specifically, suppose that expected profits, inherent to R\&D, during the $J$ pre-sample years can be represented with the equation

$$
\pi_{i t}^{*}-F_{i t}^{\mathrm{O}}=\lambda X_{i t}^{p}+\varepsilon_{i t}^{p}
$$

where $X_{i t}^{p}$ is a distributed lag in pre-sample realizations on exogenous variables. Then presample R\&D-participation is described by

$$
y_{i t}=\left\{\begin{array}{cc}
1 & \text { if } O \leq \lambda X_{i t}^{p}+\varepsilon_{i t}^{p} \\
0 & \text { otherwise }
\end{array}\right.
$$

instead of equation (10).

We assume that the pre-sample disturbance term $\left(\varepsilon_{i t}^{p}\right)$ has the same structure and properties than $\varepsilon_{i t}$. Furthermore, we allow serial correlation in disturbances to cause correlation between $y_{i t}(t>J)$ and the lagged participation variables $y_{i 1}, \ldots, y_{i J}$. We assume that the joint distribution of the error terms $\varepsilon_{i 1}^{P}, \ldots, \varepsilon_{i}^{P}, \varepsilon_{i J+1}, \ldots, \varepsilon_{i T}$, is multivariate standard normal, and it is characterised by $\{(T \times T)-T\} / 2$ free distinct (and estimable) correlations. In our empirical work $J=3$ and $T=10$. Given our assumptions, we may write the full correlation matrix as: 


$\left|\begin{array}{cccccccccc}1 & \rho_{12} & \rho_{13} & \rho_{14} & \rho_{15} & \rho_{16} & \rho_{17} & \rho_{18} & \rho_{19} & \rho_{110} \\ \rho_{21} & 1 & \rho_{23} & \rho_{24} & \rho_{25} & \rho_{26} & \rho_{27} & \rho_{28} & \rho_{29} & \rho_{210} \\ \rho_{31} & \rho_{32} & 1 & \rho_{34} & \rho_{35} & \rho_{36} & \rho_{37} & \rho_{38} & \rho_{39} & \rho_{310} \\ \rho_{41} & \rho_{42} & \rho_{43} & 1 & \rho_{45} & \rho_{46} & \rho_{47} & \rho_{48} & \rho_{49} & \rho_{410} \\ \rho_{51} & \rho_{52} & \rho_{53} & \rho_{54} & 1 & \rho_{56} & \rho_{57} & \rho_{58} & \rho_{59} & \rho_{510} \\ \rho_{61} & \rho_{62} & \rho_{63} & \rho_{64} & \rho_{65} & 1 & \rho_{67} & \rho_{68} & \rho_{69} & \rho_{610} \\ \rho_{71} & \rho_{72} & \rho_{73} & \rho_{74} & \rho_{75} & \rho_{76} & 1 & \rho_{78} & \rho_{79} & \rho_{710} \\ \rho_{81} & \rho_{82} & \rho_{83} & \rho_{84} & \rho_{85} & \rho_{86} & \rho_{87} & 1 & \rho_{89} & \rho_{810} \\ \rho_{91} & \rho_{92} & \rho_{93} & \rho_{94} & \rho_{95} & \rho_{96} & \rho_{97} & \rho_{98} & 1 & \rho_{910} \\ \rho_{101} & \rho_{102} & \rho_{103} & \rho_{104} & \rho_{105} & \rho_{106} & \rho_{107} & \rho_{108} & \rho_{109} & 1\end{array}\right|$

where there are values of 1 on the leading diagonal and correlations $\rho_{t s}=\rho_{s t}$ as off-diagonal elements. The set of correlation coefficients $\rho_{41}, \rho_{51}, \rho_{61}, \rho_{71}, \rho_{81}, \rho_{91}, \rho_{101}, \rho_{42}, \rho_{52}$,

$\rho_{62}, \rho_{72}, \rho_{82}, \rho_{92}, \rho_{102}, \rho_{43}, \rho_{53}, \rho_{63}, \rho_{73}, \rho_{83}, \rho_{93}, \rho_{103}$, summarises the association between unobservable factors determining initial conditions $R \& D$ status and sample years R\&D status. A positive (negative) sign of all of them indicates that firms which were more likely to be initially (on initial conditions years) performing R\&D were more (less) likely to remain (during sample years) R\&D suppliers compared to the non-R\&D ones. When they are jointly equal to zero, then there is no initial conditions problem: R\&D status at $1, \ldots, J$ may be treated as exogenous and the model reduces its dimension to a $\boldsymbol{T}-\boldsymbol{J}$ multivariate probit model. And if $\rho_{t s}, \forall t \neq s$, are all jointly equal to zero, then R\&D equations may be estimated using simple univariate probit models. We estimate the general model with free correlations and test whether initial conditions are exogenous and whether equation errors are serially uncorrelated.

Our model is a dynamic random effects multivariate probit model, which is estimated using maximum-likelihood (ML) techniques involving T-dimensional integrals. We solved this computational problem using simulated maximum likelihood (SML) methods. Multivariate standard normal probability distribution functions are replaced by their simulated counterparts. Accordingly, we use the Geweke-Hajivassiliou-Keane (GHK) simulator. Additionally, to control for the fact that we have repeated observations on the same supplier, we use a pseudo maximum likelihood estimator drawing on ideas from the survey statistics literature. The complex survey statistics literature has developed methods for adjusting the estimates of the parameter covariance matrix to account for sample clustering, using formulae that allow for arbitrary correlations between observations within the same sample cluster. We defined each cluster to consist of all the panel observations of a given supplier. The sample log-likelihood is a "pseudo-likelihood" in this case, from which can be derived a "robust" variance estimator of the parameter estimates using Taylor-series linearization. Our 
estimator is a Pseudo Simulated Maximum Likelihood (PSML) estimator as the pseudo-likelihood was evaluated using the GHK simulator.

\section{The explanatory variables}

To parameterise the reduced-form model given by equation (10) describing the suppliers' R\&D investment decision, we assume that variation in R\&D profitability and set-up costs (apart from unobserved characteristics) arises from the following sources: time-specific effects, supplier and market characteristics and spillovers. The inclusion of time-specific effects tries to capture macro-level changes in R\&D conditions and institutional factors such as R\&D policy variations, the business cycle, credit-market conditions, etc. Among the supplier characteristics we distinguish four different groups: economic opportunities, technological opportunities, R\&D appropriability conditions and other supplier characteristics. To proxy for appropriability conditions we follow Beneito (2003) and calculate the ratio between total number of patents granted and the total number of suppliers that assert to have achieved innovations in the suppliers' industrial sector. A number of supplier characteristics are also assumed to influence supplier's R\&D decisions. We also include the foreign capital participation and the foreign content of the suppliers' physical capital, as well as a dummy capturing the legal structure of the supplier. The decision to invest in R\&D will be also influenced by market characteristics, such as the degree of market concentration and competition. We calculate the concentration ratio of the four largest suppliers in the relevant market and account for the supplier's number of direct competitors. There is no clear-cut relationship between $R \& D$ activities and market power. Suppliers facing market competitive pressure may have incentives to innovate and obtain future market power. However, ex ante market power generates financial means to innovate and reduces risk levels. We estimate the impact of spillovers from the R\&D activities undertaken by other suppliers in the same region. We consider three separate forms of spillovers: supplier-specific, region-specific and local. Supplier-specific spillovers are captured by R\&D activities undertaken within the same supplier but outside the region where the supplier operates. Region-specific spillovers are captured by R\&D activities in the same region but different suppliers, and local spillovers are captured by the R\&D activities performed in the same supplier and region in which suppliers operate. In order to assess the importance of previous $R \& D$ experience on the suppliers current R\&D investment, we include in our estimation three lags of past R\&D investment. As noticed earlier, if sunk costs are not zero the current decision of the supplier to invest in R\&D will depend upon the supplier's R\&D history.

\section{Estimation results}

As anticipated in section 2, the final data set used to estimate equation (10), consists of 8327 observations: eleven annual observations for 757 suppliers that cover the 2003 - 2013 period. The observations for 2003- 2004 are treated as the $J$ 
$=3$ pre-sample years and are used to control for the initial conditions problem. The observations for 2003 are used as regressors for the 2004 initial conditions set. The observations for 2004-2007 are used to estimate the relevant parameters in equation 10.

\section{Table 7: Variables definition}

\begin{tabular}{|c|c|}
\hline$y_{i, t-1}$ & Dummy that takes value one if the supplier performed R\&D in year $t-1$. \\
\hline$y_{i, t-2}$ & $\begin{array}{l}\text { Dummy that takes value one if the supplier did not perform R\&D last year } \\
\text { but performed R\&D two years ago. }\end{array}$ \\
\hline$y_{i, t-3}$ & $\begin{array}{l}\text { Dummy that takes value one if the last time that the supplier performed } \\
\text { R\&D was three years ago. }\end{array}$ \\
\hline Year dummies & Dummy variables that take value 1 for the corresponding year. \\
\hline Sales growth & Growth rate of domestic sales in real terms (in \%). \\
\hline Regional market & $\begin{array}{l}\text { Dummy variable that equals } 1 \text { if the geographic limits of the supplier's } \\
\text { main market is local, provincial or regional, and } 0 \text { otherwise. }\end{array}$ \\
\hline National Market & $\begin{array}{l}\text { Dummy variable that equals } 1 \text { if the geographic limits of the supplier's } \\
\text { main market is national, and } 0 \text { otherwise }\end{array}$ \\
\hline $\begin{array}{l}\text { International- } \\
\text { National market }\end{array}$ & $\begin{array}{l}\text { Dummy variable that equals } 1 \text { if the geographic limits of the supplier's } \\
\text { main market is foreign or both national and foreign, and } 0 \text { otherwise. }\end{array}$ \\
\hline Export intensity & Exports to sales ratio (in \%). \\
\hline $\begin{array}{l}\text { Standardized } \\
\text { product }\end{array}$ & $\begin{array}{l}\text { Dummy variable that equals } 1 \text { if the supplier asserts to offer a } \\
\text { standardized product (as opposed to specifically designed for the } \\
\text { customers), and } 0 \text { otherwise }\end{array}$ \\
\hline Appropriability & $\begin{array}{l}\text { Ratio of the total number of patents over the total number of suppliers } \\
\text { that assert to have achieved innovations in the supplier's sector ( } 50 \\
\text { sectors of the survey classification) }\end{array}$ \\
\hline Labour quality & $\begin{array}{l}\text { Ratio of the number of highly qualified workers to total employment } \\
\text { (once the R\&D labour force is deducted) (in \%). }\end{array}$ \\
\hline Size1 & $\begin{array}{l}\text { Dummy variable that equals } 1 \text { if the number of workers of the supplier is } \\
\text { below or equal to } 20 \text {, and } 0 \text { otherwise. }\end{array}$ \\
\hline Size2 & $\begin{array}{l}\text { Dummy variable that equals } 1 \text { if the average number of workers of the } \\
\text { supplier is above } 20 \text { and below or equal to } 50 \text {, and } 0 \text { otherwise. }\end{array}$ \\
\hline Size3 & $\begin{array}{l}\text { Dummy variable that equals } 1 \text { if the average number of workers of the } \\
\text { supplier is above } 50 \text { and below or equal to } 100 \text {, and } 0 \text { otherwise. }\end{array}$ \\
\hline Size4 & $\begin{array}{l}\text { Dummy variable that equals } 1 \text { if the average number of workers of the } \\
\text { supplier is above } 100 \text { and below or equal to } 200 \text {, and } 0 \text { otherwise. }\end{array}$ \\
\hline Size5 & $\begin{array}{l}\text { Dummy variable that equals } 1 \text { if the average number of workers of the } \\
\text { supplier is above } 200 \text { and below or equal to } 500 \text {, and } 0 \text { otherwise. }\end{array}$ \\
\hline Size6 & $\begin{array}{l}\text { Dummy variable that equals } 1 \text { if the average number of workers of the } \\
\text { supplier is above } 500 \text {, and } 0 \text { otherwise. }\end{array}$ \\
\hline $\begin{array}{l}\text { Price-cost margin } \\
\text { (PCM) }\end{array}$ & $\begin{array}{l}\text { Approximated by the value of gross output minus variable costs of } \\
\text { production, divided by the value of gross output. The gross value output } \\
\text { is computed as sales + stock variation + other revenues. The variable cost } \\
\text { of production is computed as intermediate consumption (raw material } \\
\text { and services ) + labour costs. R\&D services have been excluded from } \\
\text { costs, and an estimation of the costs represented by R\&D personnel has } \\
\text { been deduced from the total labour costs. }\end{array}$ \\
\hline Productivity & Log of labour productivity. \\
\hline
\end{tabular}




\section{Table 7 (cont.): Variables definition}

\begin{tabular}{|c|c|}
\hline $\begin{array}{l}\text { Significant market } \\
\text { share }\end{array}$ & $\begin{array}{l}\text { Dummy variable taking the value of } 1 \text { if the supplier asserts to account } \\
\text { for a significant market share in its main market, and } 0 \text { otherwise. }\end{array}$ \\
\hline Equity-debt ratio & $\begin{array}{l}\text { This variable is computed from the balance sheet of the survey, provided } \\
\text { by the questionnaire of the survey. It is defined as the sum of total own } \\
\text { funds of the supplier over total debts }\end{array}$ \\
\hline Public sales & $\begin{array}{l}\text { Dummy variable that takes value one if more than } 25 \% \text { of supplier sales } \\
\text { go to the public sector. }\end{array}$ \\
\hline Advertising & Advertising expenditure normalized by sales (in \%). \\
\hline Foreign & $\begin{array}{l}\text { Dummy variable that takes value one if more than } 25 \% \text { of the supplier } \\
\text { shares are foreign owned. }\end{array}$ \\
\hline FEQ & Supplier's average percentage of foreign physical equipment \\
\hline Corporate & $\begin{array}{l}\text { Dummy variable that takes value one if the supplier is a limited liability } \\
\text { corporation. }\end{array}$ \\
\hline CR4 & $\begin{array}{l}\text { This is the four- supplier concentration ratio, i.e. the market share } \\
\text { accounted for by the four largest suppliers in the principal market in } \\
\text { which suppliers compete. This variable shows a high degree of no } \\
\text { response in the survey. For this reason an estimation of this variable has } \\
\text { been carried out for those suppliers that do not respond. Following } \\
\text { Huergo (1994) and Fariñas and Huergo (1994), the four- supplier } \\
\text { concentration ratio is computed from the responses of suppliers in the } \\
\text { same 'market', this market being identified taking into account the } \\
\text { supplier sector ( } 50 \text { suppliers defined from the three-digit survey } \\
\text { classification), the geographic limits in which they mainly commercialise } \\
\text { their products (local, regional, national or abroad) and the number of } \\
\text { competitors themselves claim to have in their main market. }\end{array}$ \\
\hline $\begin{array}{l}\text { Number of } \\
\text { competitors 0-10 }\end{array}$ & $\begin{array}{l}\text { Dummy variable that equals } 1 \text { if the supplier asserts to have less than (or } \\
\text { equal to) } 10 \text { competitors with significant market share in their main } \\
\text { market, and } 0 \text { otherwise. }\end{array}$ \\
\hline $\begin{array}{l}\text { Number of } \\
\text { competitors } 10- \\
25\end{array}$ & $\begin{array}{l}\text { Dummy variable that equals } 1 \text { if the supplier asserts to have more than } \\
10 \text { and less than (or equal to) } 25 \text { competitors with significant market } \\
\text { share in their main market, and } 0 \text { otherwise }\end{array}$ \\
\hline Number of & Dummy variable that equals 1 if the supplier asserts to have more than \\
\hline competitors & $\begin{array}{l}25 \text { competitors with significant market share in their main market, and } 0 \\
\text { otherwise. }\end{array}$ \\
\hline $\begin{array}{l}\text { Region-specific } \\
\text { spillovers }\end{array}$ & $\begin{array}{l}\text { Fraction of suppliers that perform R\&D in the region but outside the } \\
\text { corresponding survey ( } 20 \text { suppliers). }\end{array}$ \\
\hline $\begin{array}{l}\text { Supplier-specific } \\
\text { spillovers }\end{array}$ & $\begin{array}{l}\text { Fraction of suppliers that perform R\&D in the survey ( } 20 \text { suppliers) but } \\
\text { outside a given region. }\end{array}$ \\
\hline Local-spillovers & Fraction of suppliers that perform R\&D in the region and the survey. \\
\hline Age & Log of the number of years since the supplier was born. \\
\hline Diversification & $\begin{array}{l}\text { This variable tries to approximate the degree of differentiation of the } \\
\text { supplier's line of business. The survey provides information about the } \\
\text { main products offered by the supplier that account for at least the } 50 \% \\
\text { of its total amount of sales. Using such information, this variable has } \\
\text { been defined as the number of products that account for at least this } \\
\text { percentage. }\end{array}$ \\
\hline & supplier sectors of the survey \\
\hline
\end{tabular}


Table 8: Probit models for the decision to undertake R\&D activities

\begin{tabular}{|c|c|c|}
\hline & Coefficient & Standard Error \\
\hline$y_{i, t-1}$ & $1.891^{* * *}$ & $(0.202)$ \\
\hline$\tilde{\boldsymbol{y}}_{i, t-2}$ & 0.214 & $(0.140)$ \\
\hline$\tilde{\mathcal{Y}}_{i, t-3}$ & 0.204 & $(0.143)$ \\
\hline Year 2008 & -0.120 & $(0.100)$ \\
\hline Year 2009 & 0.014 & $(0.101)$ \\
\hline Year 2010 & -0.121 & $(0.095)$ \\
\hline Year 2011 & 0.100 & $(0.100)$ \\
\hline Year 2012 & 0.017 & (0.996) \\
\hline Year 2013 & -0.083 & $(0.101)$ \\
\hline Sales growth & $-7.0 e-05^{* *}$ & (3.6e-05) \\
\hline National market & 0.051 & $(0.074)$ \\
\hline International and National market & 0.077 & $(0.089)$ \\
\hline Export intensity & $0.067^{* *}$ & $(0.030)$ \\
\hline Standardized product & -0.050 & $(0.064)$ \\
\hline Appropriability & $0.035^{* *}$ & $(0.019)$ \\
\hline Labour quality & $0.013^{* *}$ & $(0.006)$ \\
\hline Size2 & $0.219^{* * *}$ & $(0.078)$ \\
\hline Size3 & $0.301^{* * *}$ & $(0.122)$ \\
\hline Size4 & $0.603^{* * *}$ & $(0135)$ \\
\hline Size5 & $0.910^{* * *}$ & $(0.136)$ \\
\hline Size6 & $1.175^{* * *}$ & $(0.179)$ \\
\hline PCM & $-0.002^{* * *}$ & $(0.001)$ \\
\hline Productivity & $0.131^{* * *}$ & $(0.049)$ \\
\hline Significant market share & 0.090 & $(0.061)$ \\
\hline Equity-debt ratio & $-1.67 e-05$ & $(6.8 e-05)$ \\
\hline Advertising & $0.015^{* *}$ & $(0.008)$ \\
\hline Foreign & $-0.241^{* * *}$ & $(0.087)$ \\
\hline FEQ & $0.002^{* * *}$ & $(0.001)$ \\
\hline Corporate & -0.001 & $(0.076)$ \\
\hline Concentration ratio 4 (CR4) & 0.001 & $(0.001)$ \\
\hline Number competitors <10 & -0.008 & $(0.069)$ \\
\hline Number competitors $10-25$ & 0.004 & $(0.094)$ \\
\hline Regional Spillovers & $0.008^{* *}$ & $(0.004)$ \\
\hline Industry Spillovers & -0.006 & $(0.005)$ \\
\hline Local Spillovers & 0.001 & $(0.001)$ \\
\hline Age & 0.045 & $(0.057)$ \\
\hline Public Sales & -0.095 & $(0.202)$ \\
\hline Number of products (diversification) & -0.032 & $(0.056)$ \\
\hline Food and tobacco & 0.063 & $(0.182)$ \\
\hline Beverages & 0.404 & $(0.310)$ \\
\hline Textiles & 0.286 & (0.179) \\
\hline Leather and shoes & $0.494^{* *}$ & $(0.238)$ \\
\hline Wood & 0.124 & $(0.286)$ \\
\hline Paper & 0.181 & $(0.239)$ \\
\hline Printing & -0.219 & $(0.223)$ \\
\hline Chemical products & $1.033^{* * *}$ & $(0.330)$ \\
\hline Rubber and plastic & $0.686^{* * *}$ & $(0.233)$ \\
\hline Non metallic miner & $0.483^{* * *}$ & $(0.187)$ \\
\hline Metallurgy & $0.866^{* * *}$ & $(0.340)$ \\
\hline
\end{tabular}


Suppliers Dynamic Approach to Invest in R\&D with Sunk Costs in Indian Contexts

\section{Table 8 (cont.): Probit models for the decision to undertake R\&D activities}

\begin{tabular}{lcc} 
& Coefficient & Standard Error \\
\hline Metallic products & $0.391^{* *}$ & $(0.183)$ \\
Machinery and mech. eq. & $0.915^{* * *}$ & $(0.279)$ \\
Office machines & 0.167 & $(0.381)$ \\
Electronic & $0.834^{* * *}$ & $(0.289)$ \\
Motors and cars & $0.752^{* * *}$ & $(0.267)$ \\
Other transport material & 0.324 & $(0.237)$ \\
Furniture & 0.234 & $(0.262)$ \\
Other manufacturing goods & 0.310 & $(0.240)$ \\
Intercept & $-3.908^{* * *}$ & $(0.496)$
\end{tabular}

Tests for column (1) estimations:

1. Test of joint significance of the between

periods correlation coefficients ${ }^{\mathrm{a}} \quad \chi_{45}^{2}=269.01 \quad p-$ value $=0.000$

2. Test of joint significance of the correlation between the $J \leq 3$ initial conditions periods and J>periods ${ }^{\text {b }}$

$$
\begin{array}{ll}
\chi_{45}^{2}=269.01 & p-\text { value }=0.000 \\
\chi_{21}^{2}=141.766 & p-\text { value }=0.000
\end{array}
$$

$* * *, * *, *$ indicate significance at the $1 \%, 5 \%$ and $10 \%$ respectively

${ }^{a}$ The null hypothesis of this test is:

$$
\begin{aligned}
H_{0} & : \rho_{21}=\rho_{31}=\rho_{41}=\rho_{51}=\rho_{61}=\rho_{71}=\rho_{81}=\rho_{91}=\rho_{101}=\rho_{32}=\rho_{42}=\rho_{52}=\rho_{62}=\rho_{72}==\rho_{82}=\rho_{92}=\rho_{102}= \\
& =\rho_{43}=\rho_{53}=\rho_{63}=\rho_{73}=\rho_{83}=\rho_{93}=\rho_{103}=\rho_{54}=\rho_{64}=\rho_{74}=\rho_{84}=\rho_{94}=\rho_{104}=\rho_{65}=\rho_{75}=\rho_{85}=\rho_{95}= \\
& =\rho_{105}=\rho_{76}=\rho_{86}=\rho_{96}=\rho_{106}=\rho_{87}=\rho_{97}=\rho_{107}=\rho_{98}=\rho_{108}=\rho_{109}=0
\end{aligned}
$$

${ }^{\mathrm{b}}$ The null hypothesis of this test is:

$H_{0}: \rho_{41}=\rho_{51}=\rho_{61}=\rho_{71}=\rho_{81}=\rho_{91}=\rho_{101}=\rho_{42}=\rho_{52}=\rho_{62}=\rho_{72}=\rho_{82}=\rho_{92}=\rho_{102}=$ $=\rho_{43}=\rho_{53}=\rho_{63}=\rho_{73}=\rho_{83}=\rho_{93}=\rho_{103}$

In the Table 8 we report the estimation results. This estimation includes the past participation history in R\&D activities up to a three lags structure, allows for serially correlated errors, individual effects and controls for endogeneity of initial conditions.

The result from a test of joint significance of all the $\rho$-correlation coefficients imply rejection of the null hypothesis that they are jointly equal to zero, with a $\chi_{45}^{2}=269.01$ and $p$-value approximately equal to zero. Hence, this confirms that the proper estimation method should be a multivariate probit model, as using univariate probit models we would be ignoring two possible sources of persistence: unobserved individual heterogeneity and serial correlated error terms. Furthermore, we also perform a test for the endogeneity of initial conditions by testing the joint significance of $\rho$-correlation coefficients between initial conditions errors $(\mathrm{J} \leq 3)$ and sample years errors $(\mathrm{J}>3)$. Exogeneity of initial conditions is strongly rejected, with a $\chi_{21}^{2}=141.766$ and a $p$-value approximately equal to zero. Thus, initial conditions should not be treated as exogenous. The null hypotheses of these tests can be find at the bottom of Table 7 . 


\subsection{Sunk costs parameters}

We start analysing the coefficients of $y_{i, t-1}, \tilde{y}_{i, t-2}$ and $\tilde{y}_{i, t-3}$ that capture the importance of sunk costs. A Wald test of joint significance of these three coefficients suggests to reject the hypothesis that these are jointly equal to 0 , with a $\chi_{3}^{2}$ statistic of 93.68 and a $p$-value approximately 0 . Hence, we can conclude, that even after controlling for a general form of serial correlation, past R\&D history matters. This result supports the hypothesis of the hysteresis theory that establishes the existence of sunk costs in the decision to undertake R\&D activities. As regards individual coefficients, the coefficient of $y_{i, t-1}$ is large and positive revealing that the fact that a supplier was doing R\&D activities last year has a strong positive impact on the probability of doing such activities this year. The coefficients of $\tilde{y}_{i, t-2}$ and $\tilde{y}_{i, t-3}$ measure, respectively, the reductions enjoyed by those suppliers that last performed R\&D activities two and three years ago in the full sunk costs of entry faced by a new R\&D supplier. These coefficients are non significant. These results indicate a rapid depreciation of the experience in R\&D activities: there is no significant difference between the re-entry costs of a supplier that last performed R\&D activities two or three years ago and a supplier that never did it before. Furthermore, the lack of significance of $\tilde{y}_{i, t-2}$ and $\tilde{y}_{i, t-3}$ is supporting that our choice of a three-year lag structure seems enough to capture the relevant R\&D history of a supplier.

\subsection{Time dummies, supplier characteristics and spillovers}

Next we analyse the impact of time dummies, supplier characteristics and spillovers on the expected profits net of sunk entry costs $\left(\pi_{i t}^{*}-F^{0}\right)$ of a supplier with no previous experience on undertaking R\&D activities. Although, no time dummy is significant at a 5\% level, we get that the year 2008, 2009, 2011 and 2013 dummy variables are significant at a $10 \%$ level. In addition, the hypothesis that time dummies are jointly equal to zero is not rejected (the $\chi_{6}^{2}$ test is 8.67 and the corresponding $p$-value 0.192 ). This partial lack of responsiveness in expected future profits of performing R\&D over time might indicate that these activities are not very sensitive to changes in macro-variables during the sample period, suggesting that both sunk costs and supplier characteristics are the main factors determining suppliers R\&D trajectories. We further analyse the influence of observable supplier characteristics on net profitability related to undertaking R\&D activities. In relation to variables proxiyng for economic opportunities, we get a significant and negative effect of the suppliers' sales growth on the decision to undertake R\&D activities. This result suggests that suppliers experiencing high sales' growths do not have incentives to innovate since their market are still expanding. We also find that export intensity has a significant and positive effect on the decision to invest on $R \& D$, suggesting that suppliers need to innovate more in order to face more 
competitive international markets. In relation to the technological opportunities, we introduce a set of two-digit supplier dummies. In general, we get positive and significant effects for this set of dummies and, interestingly, whenever the effects are significant, these are higher for high technological suppliers (see table 9).

\section{Table 9: Suppliers technological intensity}

\begin{tabular}{lcc}
\hline Low technological intensity & Coefficient & S.E. \\
\hline Beverages & 0.404 & $(0.310)$ \\
Textiles & 0.286 & $(0.179)$ \\
Leather and shoes & $0.494^{* *}$ & $(0.238)$ \\
Wood & 0.124 & $(0.286)$ \\
Paper & 0.181 & $(0.239)$ \\
Printing & -0.219 & $(0.223)$ \\
Non metallic miner & $0.483^{* * *}$ & $(0.187)$ \\
Metallic products & $0.391^{* *}$ & $(0.183)$ \\
Furniture & 0.234 & $(0.262)$ \\
Other manufacturing goods & 0.310 & $(0.240)$ \\
Medium technological intensity & & \\
\hline Food and tobacco & 0.063 & $(0.182)$ \\
Rubber and plastic & $0.686^{* * *}$ & $(0.233)$ \\
Metallurgy & $0.866^{* * *}$ & $(0.340)$ \\
Machinery and mech. eq. & $0.915^{* * *}$ & $(0.279)$ \\
Motors and cars & $0.752^{* * *}$ & $(0.267)$ \\
High technological intensity & & \\
\hline Chemical products & $1.033^{* * *}$ & $(0.330)$ \\
Office machines & 0.167 & $(0.381)$ \\
Electronic & $0.834^{* * *}$ & $(0.289)$ \\
Other transport material & 0.324 & $(0.237)$ \\
\hline
\end{tabular}

Beneito (2003), however, could not establish this clear cut association. Relating to financial and economic conditions under which suppliers operate, our results show that the coefficient of labour productivity is positive and significant, but the coefficient of our measure of the suppliers' price cost margin is significant and negative. This result could suggest that the better the economic conditions faced by suppliers, the lower the pressure to undertake R\&D activities. Turning to advertising intensity, which we use as a proxy for the degree of horizontal product differentiation, we find that its coefficient is positive and significant. Suppliers with higher advertising expenditures are more prone to invest in R\&D activities. Our results have confirmed that suppliers participated by foreign capital are mainly productive platforms as they are less likely to carry out R\&D activities. However, the higher the foreign content of suppliers' physical capital, the higher the probability to invest in R\&D. Regarding to the variables trying to capture market characteristics, we do not find a significant effect of the concentration ratio nor the number of competitors on the probability to undertake R\&D activities. Looking at spillovers, only regional spillovers seem to have a positive and significant impact on the probability of doing R\&D. This may suggest that the presence of other industry 
$R \& D$ investors in the same region lowers the cost of entry in the innovation market, possibly by increasing the availability of specialized inputs such as R\&D networks or workers with previous experience in R\&D. Neither industry nor local spillovers are significant.

\subsection{Goodness of fit}

As in Roberts and Vuong (2013), to evaluate the goodness of fit of our model we compare actual and predicted R\&D trajectories. For the seven-year period 2007 2013 there are $128\left(2^{7}\right)$ possible R\&D trajectories for an individual supplier. Across the 748 suppliers of our sample, some of these trajectories either are never observed or are quite unusual. Hence, to simplify the comparison of actual and predicted trajectories, we group the 128 possible trajectories into 6 categories based on two criteria: the supplier R\&D status in 2007 and whether the supplier changes R\&D status once or more between 2008 and 2013. Table 10 shows that actual and predicted frequencies for these six categories are quite similar. Furthermore, the results of a chi-square contingency table test, comparing actual and predicted frequencies ( $\chi^{2}=1.879$ with $p$-value of 0.866$)$, indicate that there are not significant differences between both of them. These results suggest that our functional form, lags structure and error structure are quite appropriate and that our model predicts quite accurately observed R\&D patterns.

\section{Table 10: Observed vs. predicted frequencies of $y_{i t}$ trajectories}

\begin{tabular}{lcc}
\hline Trajectory type & $\begin{array}{c}\text { Observed } \\
\text { frequencies }\end{array}$ & $\begin{array}{c}\text { Predicted } \\
\text { frequencies }\end{array}$ \\
\hline Always non R\&D supplier & 0.493 & 0.508 \\
Begin as non R\&D supplier, switch once & 0.082 & 0.076 \\
Begin as non R\&D supplier, switch at least twice & 0.099 & 0.091 \\
Always an R\&D supplier & 0.214 & 0.214 \\
Begin as R\&D supplier, switch once & 0.048 & 0.040 \\
Begin as R\&D supplier, switch at least twice & 0.064 & 0.071 \\
\hline
\end{tabular}

\subsection{Robustness Check}

To check whether the fixed effect model is applicable to this study the author uses the Hausman specification test. The test compares the fixed versus random effects that the individual effects are uncorrelated with the error in the model (Hausman 1978). If the variables trying to capture market characteristics, we do not find a significant effect, a random effects model produces biased estimators. When Hausman specification test was performed, the results ( $p$-value $=0.00$, the $\mathrm{H}_{0}$ for random effects is rejected) suggested the use of fixed effects. The author also looks at the F-test, a joint test of significance of regression coefficients. It tests for the joint hypothesis that all coefficients, except the intercept, are equal to zero. Since panel data specification is included, the author finds it important to test for autocorrelation. Autocorrelation arises when the assumption of no-serial 
correlation is violated, meaning that the error terms of two different periods may be related. To check if there is presence of autocorrelation in the model, the author uses the Durbin- Watson test (1950). A value of DW close to 2 indicates that the first-order autocorrelation coefficient $p$ is close to zero and there is no first order autocorrelation. If DW is 'much smaller' than 2, this is an indication for positive autocorrelation. To deal with autocorrelation the author used White standard errors andincluded the lagged dependent variable as suggested by Verbeek (2012:125). As an additional robustness check, the author has performed the same models which cover the pre-crisis period, from 2003 till 2013. Apart from the results presented in Table 10 for the results of a chi-square contingency, we conducted several additional analyses to check the robustness of our results. First, before estimating our equations by 3SLS we undertook Durbin-Wu-Hausman (DWH) test for endogeneity in our equations, which compares the parameters estimated by OLS with the parameters estimated by simultaneous equations model, using instrumental variables. If there is no significant difference in the parameter estimates that the exogenous is accepted and OLS will provide unbiased parameter estimates. In our case the exogeneity was rejected indicating endogeneity in our equations $(p<0.01)$. Second, while the strength of instruments was confirmed based on their significance in estimating the endogenous variables (all instrumental variables were significant in Models 1:1 and 2:1, Table 9) we conducted additional instrument validity tests. In particular, we conducted the Sargan-Hansen test, a test of over identifying restrictions. The positive autocorrelation is that the instruments are valid instruments, i.e., uncorrelated with the error term, and that the excludedinstruments are correctly excluded from the estimated equation. A rejection casts doubt on the validity of the instruments. The result ofSargan/Hansen test showed that our instruments are valid as $(p<0.44)$. Third, we considered alternative estimation techniques. We estimated equations (1) and (2) using two stage least squares (2SLS) and instrumental variable regression with Generalized Method of Moments (GMM) estimation. Our results remain consistent with the reported results when we use 2 SLS and GMM estimators in our regression analysis. Fourth, we analyzed models with a 7 year lag specification for innovative output below (above) aspiration, a 4 year lag for undertaking R\&D activities, and 7 year lag for control and instrumental variables, with respect to the current innovative output; our results remained similar. Finally, we estimated our models with an innovative performance variable calculated in a different way. More specifically, we calculated the average innovative performance of firms based on a five year moving window. Then we included 10 year lag of innovative performance, 5 year lag of undertaking R\&D activities, and 10 year lag of the control and instrumental variables with respect to the current innovative performance in both our equations (1) and (2). As a result of analysis of this specification we found that there is a negative relationship between past performance and the number of $R \& D$ activities and there is a positive relationship between $R \& D$ activities and current innovative performance. This finding 
corroborates our findings reported here and suggests that the weaker (stronger) the past innovative performance the higher (lower) the number of R\&D activities and that R\&D activities positively influences current innovative performance after accounting for its endogeneity.

\section{Conclusions}

Our analysis has confirmed the existence of sunk costs in suppliers' R\&D activities. In a dynamic framework and using panel data, we have rejected the null hypothesis that sunk costs related to starting and leaving R\&D activities are not important when suppliers have to decide whether to start or not R\&D activities. Thus, we have found evidence supporting the sunk costs as the main explanation of the observed supplier persistence in and out of R\&D activities. Our estimation results have indicated that those suppliers that leave R\&D activities suffer a rapid depreciation of their experience. Re-entry costs that faces a supplier that last performed R\&D two years ago are not significantly different from those faced by a supplier that have never undertook R\&D activities before. This phenomenon could be suggesting that $R \& D$ activities take place in a rapidly changing environment and that the ability to work in this environment depreciates fairly quickly once a supplier quits R\&D activities. Supplier heterogeneity has shown to be also an important source of persistence in R\&D activities as both observed and unobserved supplier characteristics are important to explain suppliers' R\&D trajectories. Regarding to the suppliers' economic opportunities, the probability of undertaking $R \& D$ increases with export intensity. Among suppliers' technological opportunities, we have found that the higher degree of appropriability of R\&D results, the higher the probability of performing R\&D. Suppliers in high technological industries also are more prone to invest in R\&D. Larger, more productive and more skilled labour force suppliers show a higher propensity to undertake R\&D activities. Suppliers that horizontally differentiate their products by means of advertising also have a higher probability of exporting. Our results have confirmed that suppliers participated by foreign capital are mainly productive platforms as they are less likely to carry out R\&D activities. However, the higher the foreign content of suppliers' physical capital, the higher the probability to invest in R\&D. Only regional spillovers have a positive impact on the probability of performing R\&D. The combined importance of sunk costs and supplier characteristics in the probability of investing in R\&D suggest possible R\&D promotion policies. On the one hand, policies directed at providing information and access R\&D activities or creating R\&D networks could reduce the sunk costs of entry. On the other hand, policies aimed to help suppliers to increase productivity, to stimulate product differentiation behaviours or to participate in the export market would have a positive impact on the probability of performing R\&D. 


\section{Limitations}

We acknowledge a number of limitations to this study. First, this study was limited to focus on the sunk costs in suppliers' $R \& D$ activities only; these were selected based on the fact that managers mentioned them frequently during our field interviews. Further, results suggest that they plan an important role in exploring the variance in project outcomes. Second, quantified performance outcomes measures were not included, nor were there quantified measures of sunk costs in suppliers' R\&D activities. We did, however, examine the correlations between subjective measures of performance and actual performance outcomes. Third, the effects of multiple industry respondents were not controlled for, and future studies should assess whether industry in fact does contribute to the variance in our results. Fourth, we relied on only two or three items for each construct, which is unlikely to capture the full domain of these concepts. We recognize this limitation to the study likely is due to the fact that the measures were new and that no previous measures of sunk costs in suppliers' R\&D activities had been tested formally for convergent validity. We recognize that using new measures is always a risk, but we felt it was important to capture the key variables that emerged from the case studies and had to rely on developing new scales. Researchers pursuing work in this area may use our scales as a starting point for developing a stronger set of measurement items.

\section{Future Research Directions}

In most studies only two aspects are surveyed, sunk costs and completion effects, which by far do not cover a realistic decision scenario. One aspect which should be improved in future research on sunk-cost effects is that exactly this effect is measured and that it is not mixed up with any other figure. Laboratory research might have failed to capture the complexity of real-world escalation. They suggest focusing future research on a possible relationship between preferences and escalation. Another topic which could lead to further managerial implication would be to survey the influence of payment depreciation on the willingness to repurchase a product. The results obtained from this study clearly show the importance of sunk costs in suppliers' R\&D activities but also generate a set of new and interesting research questions. A set of additional issues that build on our empirical approach include the following:

- What are the key dimensions of explicit and tacit capabilities of suppliers that can predict the likelihood of sunk costs in suppliers' R\&D activities effort? For example, how should managers weigh the relative strengths and weaknesses of various suppliers in areas such as technological knowledge, manufacturing capabilities, and length of relationship with the supplier, degree of trust, and alignment of technology roadmaps with future products in contexts of sunk costs in suppliers' R\&D activities? 
- What are the key variables of sunk costs in suppliers' R\&D activities should consider in measuring the relative alignment of a supplier's technology roadmap with its customer's product requirements?

- What are the means to gain access to and to assess the degree of alignment of sunk costs in suppliers' R\&D activities roadmaps across multiple industries on a global basis? This type of research would involve understanding the nature of product development organizational structures, as well as an assessment of the role of advanced technology groups and technology boundary spanners.

- In cases when a future required product/process technology does not exist in the market, what are the key variables to consider whether to redirect a sunk costs in suppliers' R\&D activities roadmap (outsource technology development) or to undertake the development of a new technology in-house (in source technology development)? This line of thinking takes the concept of technology uncertainty a step further by proposing that sunk costs in suppliers' R\&D activities always may not be the best solution.

- How to differentiate the general purpose technology (GPT) from ordinary product innovation achievement? What if one's research achievement happens to be similar to another's? How to explicitly melt the research paralleling to the supplier's decision into a unified general equilibrium framework with the sunk costs in suppliers' R\&D activities simultaneously treated? Quantitatively, how much of the technical fluctuation is due to the supplier's subjective adjustment and how much can be accounted by the indeterminate nature of the product innovation process per se? All these significant and challenging questions have not received adequate treatment in this paper by far, for this paper is only the preliminary step toward the deeper exploration in this area, presumably still more problems are waiting ahead for our effort

These questions represent challenges for the next decade; we believe they can benefit from prior insights derived from the literature on sunk costs in suppliers' R\&D activities. In order to understand fully how sunk costs in suppliers' R\&D activities will unfold, we further believe that the focus should not be limited to single buying/supplying organizational units but should extend both up and down the supply chain. This framework would represent better the vision of the future, wherein entire supply chains of sunk costs in suppliers' R\&D activities will compete against similarly aligned chains, with the objective of creating the maximum value up and down the chain.

\section{Acknowledgements}

We thank the reviewers for his/her thorough review and highly appreciate the comments and suggestions, which significantly contributed to improving the quality of the publication. 


\section{References}

Astrebo, T. and Simons, K.L., (2003), "Innovation exit: why entrepreneurs pull the plug on their innovations, mimeo, Department of Management Sciences, University of Waterloo, Canada.

Aw, Bee Yan, Mark J. Roberts, and Daniel Y. X., (2011), "R\&D Investment, Exporting and Productivity Dynamics," The American Economic Review, 101, (4), 1312-1344.

Beneito, P., (2002), "Technological patterns among Spanish manufacturing firms", Entrepreneurship and Regional Development, 14, 89-115.

Beneito, P., (2003), "Choosing among alternative technological strategies: an empirical análisis of formal sources of innovation", Research Policy, 32, 693-713.

Cerulli G. and Potì B., (2012), "Designing ex-post assessment of corporate RDI policies: conceptualization, indicators and modeling", World Review of Science, Technology and Sustainable Development, 9 (2/3/4), 96-123.

Clarysse B., Wright M. and Mustar P., (2009), "Behavioural additionality of R\&D subsidies: A learning perspective", Research Policy, 38, 1517-1533.

Czarnitzki D., Ebersberger B. and Fier A., (2007), "The Relationship between R\&D collaboration, Subsidies and R\&D Performance: empirical evidence from Finland and Germany", Journal of Applied Econometrics, 22, 1347-1366.

Doraszelski, U. and Jaumandreu, J., (2013), "R\&D and Productivity: Estimating Endogenous Productivity," Review of Economic Studies, 80, 1338-1383.

Hitt, M.A., Ireland, R.D., and Lee, H., (2000), "Technological learning, knowledge management, firm growth and performance: an introductory essay", Journal of Engineering and Technology Management, 17, 3/4, 231-246.

Kamien, M. and Zang, I., (2000), "Meet me halfway: research joint ventures and absorptive capacity", International Journal of Industrial Organization, 18, 995-1012.

Kaplan, T.R., Luski, I. and Wettstein, D., (2003), "Innovative activity and sunk cost", Intenational Journal of Industrial Organization, 21 (8), 1111-1133.

Roberts, M. J. and Vuong, V. A., (2013), "Empirical Modeling of R\&D Demand in a Dynamic Framework," Applied Economic Perspectives and Policy, 35(2), 185-205.

Romijn, H. and Albaladejo, M., (2002), "Determinants of innovation capability in small electronics and software firms in southeast England", Research Policy, 31, 1053-1067.

Utterback, J., (1994), "Mastering the dynamics of innovation", Harvard Business School Press, Cambridge, MA.

Veugelers, R., (1997), "Internal R\&D expenditures and external technology sourcing", Research policy, 26, 303-306. 


\section{Appendices}

\section{Table A.1: Supplier classification}

\begin{tabular}{cl}
\hline Code & Sectors \\
\hline 1 & Meat industry \\
2 & Food and tobacco \\
3 & Beverages \\
4 & Textiles \\
5 & Leather and shoes \\
6 & Wood \\
7 & Paper Industry \\
8 & Printing and printing stuff \\
9 & Chemical products \\
10 & Rubber and plastic products \\
11 & Non metallic miner products \\
12 & Metallurgy \\
13 & Metallic products \\
14 & Machinery and mechanic equipment \\
15 & Office machines \\
16 & Electronic and electric machinery and material \\
17 & Motors and cars \\
18 & Other transport material \\
19 & Furniture \\
20 & Other manufacturing goods \\
\hline
\end{tabular}

Table A2: Actual and predicted frequencies

\begin{tabular}{|c|c|c|c|c|c|c|c|c|c|c|c|c|c|c|c|c|c|}
\hline \multicolumn{7}{|c|}{ R\&D activities status } & \multirow[b]{2}{*}{$\begin{array}{c}\text { Actual } \\
\text { Frequency }\end{array}$} & \multirow[b]{2}{*}{$\begin{array}{l}\text { Expected } \\
\text { Frequency }\end{array}$} & \multicolumn{7}{|c|}{ R\&D activities status } & \multirow[b]{2}{*}{$\begin{array}{c}\text { Actual } \\
\text { Frequency }\end{array}$} & \multirow[b]{2}{*}{$\begin{array}{l}\text { Expected } \\
\text { Frequency }\end{array}$} \\
\hline 2007 & 08 & 09 & 10 & 11 & 12 & 13 & & & 2007 & 08 & 09 & 10 & 11 & 12 & 13 & & \\
\hline 1 & 1 & 1 & 1 & 1 & 1 & 1 & 0.2140 & 0.2139 & 0 & 1 & 1 & 1 & 1 & 1 & 1 & 0.0092 & 0.0094 \\
\hline 1 & 1 & 1 & 1 & 1 & 1 & 0 & 0.0092 & 0.0040 & 0 & 1 & 1 & 1 & 1 & 1 & 0 & 40 & 0.0040 \\
\hline 1 & 1 & 1 & 1 & 1 & 0 & 1 & 56 & 13 & 0 & 1 & 1 & 1 & 1 & 0 & 1 & & 027 \\
\hline 1 & 1 & 1 & 1 & 1 & 0 & 0 & 0. & 2 & 0 & 1 & 1 & 1 & 1 & 0 & 0 & & 53 \\
\hline 1 & 1 & 1 & 1 & 0 & 1 & 1 & 0. & 3 & 0 & 1 & 1 & 1 & 0 & 1 & 1 & & 13 \\
\hline 1 & 1 & 1 & 1 & 0 & 1 & 0 & 0. & & 0 & 1 & 1 & 1 & 0 & 1 & 0 & & \\
\hline 1 & 1 & 1 & 1 & 0 & 0 & 1 & 0.00 & 40 & 0 & 1 & 1 & 1 & 0 & 0 & 1 & & 0000 \\
\hline 1 & 1 & 1 & 1 & 0 & 0 & 0 & 0.00 & & 0 & 1 & 1 & 1 & 0 & 0 & 0 & & 0000 \\
\hline 1 & 1 & 1 & 0 & 1 & 1 & 1 & $0.0 c$ & & 0 & 1 & 1 & 0 & 1 & 1 & 1 & & 027 \\
\hline 1 & 1 & 1 & 0 & 1 & 1 & 0 & 0.00 & 0 & 0 & 1 & 1 & 0 & 1 & 1 & 0 & 00 & 0.0013 \\
\hline 1 & 1 & 1 & 0 & 1 & 0 & 1 & 0.00 & 00 & 0 & 1 & 1 & 0 & 1 & 0 & 1 & 0.0000 & 0.0000 \\
\hline 1 & 1 & 1 & 0 & 1 & 0 & 0 & 0.00 & 0 & 0 & 1 & 1 & 0 & 1 & 0 & 0 & 0 & 0.0000 \\
\hline 1 & 1 & 1 & 0 & 0 & 1 & 1 & 0.0 & 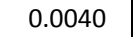 & 0 & 1 & 1 & 0 & 0 & 1 & 1 & 0.0 & 0.0000 \\
\hline 1 & 1 & 1 & 0 & 0 & 1 & 0 & 0.0 & & 0 & 1 & 1 & 0 & 0 & 1 & 0 & & 00 \\
\hline 1 & 1 & 1 & 0 & 0 & 0 & 1 & $0 .($ & & 0 & 1 & 1 & 0 & 0 & 0 & 1 & & 00 \\
\hline 1 & 1 & 1 & 0 & 0 & 0 & 0 & 0.0 & & 0 & 1 & 1 & 0 & 0 & 0 & 0 & & 27 \\
\hline 1 & 1 & 0 & 1 & 1 & 1 & 1 & & & 0 & 1 & 0 & 1 & 1 & 1 & 1 & & \\
\hline 1 & 1 & 0 & 1 & 1 & 1 & 0 & 0.0013 & 0.0000 & 0 & 1 & 0 & 1 & 1 & 1 & 0 & 0.0000 & 0.0000 \\
\hline
\end{tabular}


Suppliers Dynamic Approach to Invest in R\&D with Sunk Costs in Indian Contexts

Table A2 (cont.): Actual and predicted frequencies

\begin{tabular}{|c|c|c|c|c|c|c|c|c|c|c|c|c|c|c|c|c|c|}
\hline \multicolumn{7}{|c|}{ R\&D activities status } & \multirow[b]{2}{*}{$\begin{array}{c}\text { Actual } \\
\text { Frequency }\end{array}$} & \multirow[b]{2}{*}{$\begin{array}{c}\text { Expected } \\
\text { Frequency }\end{array}$} & \multicolumn{7}{|c|}{ R\&D activities status } & \multirow[b]{2}{*}{$\begin{array}{c}\text { Actual } \\
\text { Frequency }\end{array}$} & \multirow[b]{2}{*}{$\begin{array}{l}\text { Expected } \\
\text { Frequency }\end{array}$} \\
\hline 2007 & 08 & 09 & 10 & 11 & 12 & 13 & & & 2007 & 08 & 09 & 10 & 11 & 12 & 13 & & \\
\hline 1 & 1 & 0 & 1 & 1 & 0 & 1 & 0.0000 & 0.0000 & 0 & 1 & 0 & 1 & 1 & 0 & 1 & 0.0000 & 0.0000 \\
\hline 1 & 1 & 0 & 1 & 1 & 0 & 0 & 0.0013 & 0 & 0 & 1 & 0 & 1 & 1 & 0 & 0 & 0 & 0013 \\
\hline 1 & 1 & 0 & 1 & 0 & 1 & 1 & 0.0 & 0 & 0 & 1 & 0 & 1 & 0 & 1 & 1 & 10 & 0000 \\
\hline 1 & 1 & 0 & 1 & 0 & 1 & 0 & $0 . C$ & & 0 & 1 & 0 & 1 & 0 & 1 & 0 & 10 & 00 \\
\hline 1 & 1 & 0 & 1 & 0 & 0 & 1 & 0.0 & 0000 & 0 & 1 & 0 & 1 & 0 & 0 & 1 & 0 & 0000 \\
\hline 1 & 1 & 0 & 1 & 0 & 0 & 0 & 0. & 0 & 0 & 1 & 0 & 1 & 0 & 0 & 0 & & 00 \\
\hline 1 & 1 & 0 & 0 & 1 & 1 & 1 & $0 . C$ & 0 & 0 & 1 & 0 & 0 & 1 & 1 & 1 & & 13 \\
\hline 1 & 1 & 0 & 0 & 1 & 1 & 0 & 0. & & 0 & 1 & 0 & 0 & 1 & 1 & 0 & & \\
\hline 1 & 1 & 0 & 0 & 1 & 0 & 1 & 0. & & 0 & 1 & 0 & 0 & 1 & 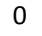 & 1 & & \\
\hline 1 & 1 & 0 & 0 & 1 & 0 & 0 & 0. & & 0 & 1 & 0 & 0 & 1 & 0 & 0 & & \\
\hline 1 & 1 & 0 & 0 & 0 & 1 & 1 & & & . & 1 & 0 & 0 & 0 & 1 & 1 & & \\
\hline 1 & 1 & 0 & 0 & 0 & 1 & 0 & & & 0 & 1 & 0 & 0 & 0 & 1 & 0 & & \\
\hline 1 & 1 & 0 & 0 & 0 & 0 & 1 & & & 0 & 1 & 0 & 0 & 0 & . & 1 & & \\
\hline 1 & 1 & 0 & 0 & 0 & 0 & 0 & & & 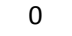 & 1 & 0 & 0 & 0 & 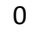 & 0 & & \\
\hline 1 & 0 & 1 & 1 & 1 & 1 & 1 & & & 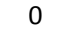 & 0 & 1 & 1 & 1 & $\perp$ & 1 & & \\
\hline 1 & 0 & 1 & 1 & 1 & 1 & 0 & & 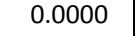 & 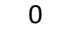 & 0 & 1 & 1 & 1 & 1 & 0 & & \\
\hline 1 & 0 & 1 & 1 & 1 & 0 & 1 & & & 0 & 0 & 1 & 1 & 1 & 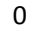 & 1 & & \\
\hline 1 & 0 & 1 & 1 & 1 & 0 & 0 & & & 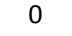 & 0 & 1 & 1 & 1 & 0 & 0 & & o0 \\
\hline 1 & 0 & 1 & 1 & 0 & 1 & 1 & & & 0 & 0 & 1 & 1 & 0 & 1 & 1 & & \\
\hline 1 & 0 & 1 & 1 & 0 & 1 & 0 & & & $v$ & 0 & 1 & 1 & 0 & 1 & 0 & & o0 \\
\hline 1 & 0 & 1 & 1 & 0 & 0 & 1 & & & 0 & 0 & 1 & 1 & 0 & 0 & 1 & & \\
\hline 1 & 0 & 1 & 1 & 0 & 0 & 0 & & & 0 & 0 & 1 & 1 & 0 & 0 & 0 & & 21 \\
\hline 1 & 0 & 1 & 0 & 1 & 1 & 1 & & & 0 & 0 & 1 & 0 & 1 & 1 & 1 & & \\
\hline 1 & 0 & 1 & 0 & 1 & 1 & 0 & & & 0 & 0 & 1 & 0 & 1 & 1 & 0 & & 0 \\
\hline 1 & 0 & 1 & 0 & 1 & 0 & 1 & & & 0 & 0 & 1 & 0 & 1 & 0 & 1 & & \\
\hline 1 & 0 & 1 & 0 & 1 & 0 & 0 & & & 0 & 0 & 1 & 0 & 1 & 0 & 0 & & \\
\hline 1 & 0 & 1 & 0 & 0 & 1 & 1 & & & 0 & 0 & 1 & 0 & 0 & 1 & 1 & & \\
\hline 1 & 0 & 1 & 0 & 0 & 1 & 0 & & & 0 & 0 & 1 & 0 & 0 & 1 & 0 & & 3 \\
\hline 1 & 0 & 1 & 0 & 0 & 0 & 1 & & & 0 & 0 & 1 & 0 & 0 & 0 & 1 & & \\
\hline 1 & 0 & 1 & 0 & 0 & 0 & 0 & & & 0 & 0 & 1 & 0 & 0 & 0 & 0 & & 53 \\
\hline 1 & 0 & 0 & 1 & 1 & 1 & 1 & & & 0 & 0 & 0 & 1 & 1 & 1 & 1 & & \\
\hline 1 & 0 & 0 & 1 & 1 & 1 & 0 & & & 0 & 0 & 0 & 1 & 1 & 1 & 0 & & 0 \\
\hline 1 & 0 & 0 & 1 & 1 & 0 & 1 & & & 0 & 0 & 0 & 1 & 1 & 0 & 1 & & \\
\hline 1 & 0 & 0 & 1 & 1 & 0 & 0 & & & c & 0 & 0 & 1 & 1 & 0 & 0 & & \\
\hline 1 & 0 & 0 & 1 & 0 & 1 & 1 & & & 0 & 0 & 0 & 1 & 0 & 1 & 1 & & \\
\hline 1 & 0 & 0 & 1 & 0 & 1 & 0 & & & 0 & 0 & 0 & 1 & 0 & 1 & 0 & & \\
\hline 1 & 0 & 0 & 1 & 0 & 0 & 1 & & & c & 0 & 0 & 1 & 0 & 0 & 1 & & 0 \\
\hline 1 & 0 & 0 & 1 & 0 & 0 & 0 & & & c & 0 & 0 & 1 & 0 & 0 & 0 & & \\
\hline 1 & 0 & 0 & 0 & 1 & 1 & 1 & & & 0 & 0 & 0 & 0 & 1 & 1 & 1 & & \\
\hline 1 & 0 & 0 & 0 & 1 & 1 & 0 & & & c & 0 & 0 & 0 & 1 & 1 & 0 & & \\
\hline 1 & 0 & 0 & 0 & 1 & 0 & 1 & & & c & 0 & 0 & 0 & 1 & 0 & 1 & & \\
\hline 1 & 0 & 0 & 0 & 1 & 0 & 0 & & & c & 0 & 0 & 0 & 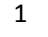 & 0 & 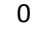 & & 53 \\
\hline 1 & 0 & 0 & 0 & 0 & 1 & 1 & & & 0 & 0 & 0 & 0 & 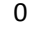 & 1 & 1 & 19 & 01 \\
\hline 1 & 0 & 0 & 0 & 0 & 1 & 0 & & & 0 & 0 & 0 & 0 & 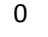 & 1 & 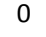 & 06 & 0094 \\
\hline 1 & 0 & 0 & 0 & 0 & 0 & 1 & & & 0 & 0 & 0 & 0 & 0 & 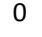 & 1 & 185 & 0.0174 \\
\hline 1 & 0 & 0 & 0 & 0 & 0 & 0 & 0.0172 & 0.0160 & 0 & 0 & 0 & 0 & 0 & 0 & 0 & 0.4927 & 0.5080 \\
\hline
\end{tabular}

